\title{
Elucidating mitochondrial DNA-markers of Ogurabased CMS linesin Indian cauliflowers (Brassica oleracea var. botrytis $L$.) and their floral abnormalities due to diversity in cyto-nuclear interaction
}

\author{
Saurabh Singh \\ Indian Agricultural Research Institute \\ Reeta Bhatia \\ Indian Agricultural Research Institute \\ Raj Kumar \\ Indian Agricultural Research Institute \\ Tusar K. Behera \\ Indian Agricultural Research Institute \\ Khushboo Kumari \\ Indian Agricultural Research Institute \\ Achintya Pramanik \\ Indian Agricultural Research Institute \\ Hemant Ghemeray \\ Indian Agricultural Research Institute \\ Kanika Sharma \\ Indian Agricultural Research Institute \\ R. C. Bhattacharya \\ National Institute if Plant Biotechnology \\ Shyam Sundar Dey ( $\nabla$ ssdey@iari.res.in ) \\ Indian Agricultural Research Institute https://orcid.org/0000-0001-9211-8820
}

\section{Research article}

Keywords: Cauliflower, cytoplasmic male sterility, cytoplasm effects, mitotype-specific markers, sequence analysis, cytoplasmic-nuclear interactions, floral reproductive traits

Posted Date: April 1st, 2020

DOI: https://doi.org/10.21203/rs.3.rs-18408/v1

License: (c) (i) This work is licensed under a Creative Commons Attribution 4.0 International License. Read Full License 


\section{Abstract}

Background: Mitochondrial markers can be used to differentiate diverse mitotypes as well as cytoplasms in angiosperms. In cauliflower, cultivation of hybrids is pivotal in remunerative agriculture and cytoplasmic male sterile lines constitute an important component of the hybrid breeding. Thus, the breeders look for utilizing diverse male sterile cytoplasms in hybrid progamme. In diversifying source of male sterility,it is essential to appropriately differentiate among the available male sterile cytoplasms in cauliflower.PCR polymorphism atthe key mitochondrial genes associated with male sterility will be useful in developing mitochondria specific markers for the different male sterile cytoplasms. Also, the auto and alloplasmic cytonuclear combinations result in complex floral abnormalities. Thus, the study aimed at developing mitotype specific markers of the sterile cytoplasms and to unravel thegenetic effects of the cytonuclear interactions on flower morphology in Indian cauliflowers.

Results: In PCR based analysis using a set of primers targeted to orf-138, 76 Indian cauliflower lines showed presence of Ogura cytoplasm though amplicons showed polymorphism within the ofr-138 sequence. The polymorphic loci were found to be spanning over 200-280 bp and 410-470bp genomic regions of BnTR4 and orf125, respectively. Sequence analysis revealed that such cytoplasmic genetic variations could be due to single nucleotide polymorphisms and insertion or deletions of 31/51 nucleotides. The cytoplasmic effects on varying nuclear-genetic backgrounds led to varying degree of floral malformations ranging from reduction in flower size, stamens and style length, modification in position of styleand anthers, absence of non-functional stamens to other floral abnormalities. These floral malformations caused dysplasia of flower structure affecting female fertility and inefficient nectar production.

Conclusions: The mitochondria specific markers can distinguish ogurabased male sterile cytoplasm. Large number of Indian cauliflower lines showed mitotype variations even within the ogura based cytoplasm. Variable nucleocytoplasmic interactions resulted into diverse type of floral malformationsin addition to pollen sterility even within the group of ogura based CMS lines. The finding provide important reference ameliorate understanding of mechanism of cytonuclear interactions in floral organ development in Brassicas. The study will help the breeders in selecting CMS lines without any floral abnormalities in $B$. oleracea.

\section{Background}

Mitochondria are primarily maternally inherited, semi-autonomous, endosymbiotic complex organelles in eukaryotic cells [1-2].Mitochondria play a central role in energy production by oxidative phosphorylation, apoptosis and other cellular processes [2, 3]. The migration of essential genes from mitochondrial genome to nuclear genome has been a consistent feature of genome evolution in eukaryotic organisms and thus mitochondrial genomes in many organisms comprise ofan incomplete set of essential genes required for their autonomous function [4-5]. Simultaneously, mitochondria participate in retrograde signaling and regulate the nuclear gene expression [5-6]. Hence, integrated action of mitochondrial and nuclear genomes is pivotal for many of the cellular functions. As compared to most of the metazoan mitochondrial genomes, the plant mitochondrial genomes are considerably larger with extensive variation in genomesize and are complex in structure. The substantial structural complexity and variation in genome size of plant mitochondrial genome is resulted from the accumulation of diverse repeat sequences, frequent homologous recombination of large repeat sequences and inclusion of foreign DNA fragments $[2,7-9]$. The plant mitogenomes also have the remarkable features of presence of highly diverse inter-genetic regions, frequent mt-DNA rearrangements, slow evolution in mtDNA sequences and rapid structural evolution [2, 79]. On account of these characteristics, the extensive genome reorganization and shuffling in gene order may occur 
in plant mitogenomes and unusual open reading frames (ORFS) are generated, some of which causes extreme phenotypes such as cytoplasmic male sterility (CMS) [2, 10-11].

The CMS is a maternally inherited trait which is characterized by inability to produce viable pollen or male reproductive organs for sexual fertilization $[2,5-6]$. The mitochondrial genes determining CMS phenotype can be masked by fertility restorer genes $(R f)$ in nuclear genome. Presence of male sterile cytoplasm without the $R f$ gene in the nuclear genome results in CMS phenotype $[2,6,11]$. CMS is an important trait to provide new insights into plant nuclear-mitochondrial communication. Cytoplasm induced male sterility is a widespread phenomenon reported in over 150 plant species $[2,6,12]$. The CMS system is instrumental for utilization of heterosis in vegetables Brassicas for higher yield and quality traits [13-17]. Cauliflower (Brassica oleracea var. botrytis L.) is an important member of vegetableBrassicasgrown worldwide. It has been an important contributor in human diet owing to high content of dietary minerals, vitamins, glucosinolates and other phytochemical compounds with antioxidant and anticancer properties $[13-14,18]$. Availability of genetic mechanisms like sporophytic self-incompatibility (SSI) and CMS make the hybrid breeding in cauliflower remunerative [15-19]. However, non-availability of strong S alleles for reliable SSI system and instability of the S alleles under varied climatic conditions made this system less attractive. Therefore, presently cytoplasm induced male sterility are most widely used in hybrid breeding in cauliflower $[13,19]$. The wild allies and other closely related Brassica coenospecies serve as the reservoir of different cytoplasms whichare being used to develop CMS throughintraspecific/interspecific/intergeneric hybridization mediated by sexual crossing or protoplast fusion [11, 20-24]. Among the different CMS types, ogu[25]and po/26]CMS systems are widely used in hybrid breeding of vegetableBrassicas. Once developed the CMS phenotype and the associated mitochondrial genes exhibit a maternal inheritance pattern.Numerous CMS related genes (orfs) have been identified and well characterized in different plant species. The key mitochondrial genes (orfs) associated with different CMS typesin Brassicaceae are orf138 correlated with Ogura CMS [21, 25], orf125 associated with kosenaCMS of Radish [27], orf72 correlated with murCMS of Diplotaxismuralis[28], orf222 associated with'nap CMS of Brassica napus[29], orf224/atp6correlated with po/ CMS [26, 30], orf288 linked with hauCMS of $B$. juncea[31], orf263 correlated with 'tour CMS of Brassica tourneforti[32], and orf220 associated with 'tuber mustard CMS' of Brassica juncea[33]. The gene specific primers for these mitochondrial genomic regions can beefficiently utilizedto differentiate different CMS types in Brassica crops. The complete mitochondrial genome sequence of many Brassica species and other important genera belonging to Brassicaceae (e.g. Arabidopsis, Radish) are available which can be mined for developing markers for differentiating differentcytoplasm responsible for male sterility $[2,10,34-36]$. Several mitochondrial DNA specific microsatellites(mt-SSR) markers have been developed to distinguish different CMS types and assessment of cytoplasmic diversity in different Brassica species likeB. oleracea var. italica[23, 37], $B$. oleracea var. capitata[38], B. rapa[39-41], B. napus[39] and B. juncea[42].

The CMS cauliflowers and other Brassica crops with Ogura or other alien cytoplastsdisplay complex variations in reproductive features. These reproductive phenotypes are expressed as floral abnormalities such as homeotic- like transformation of stamens to pistil like structures (pistillody), homeotic modification of stamens to petal like structures (petaloidy), carpelloid stamens, adherence of functional stamens to style, partially opened flowers, splitted style with exposed ovule, splitted style, absence of nectaries, rudimentary nectaries and fused flowers [11, 21-22, 43-45].These floral malformations are result of incongruity between nuclear and mitochondrial genomes [11, $37,43]$. It is evident that loss of function, mutation or insertion/deletion in MADS-box genes APETALA2, APETALA3 or PISTILLATA, which are class $\mathrm{B}$ genes of classic $A B C$ model for flower development, renders homeotic transformation of stamens to carpels or petals to sepals [37, 46-47].The homeotic floral deformities have also been explained by the dosage imbalance of class $B$ and class $C$ genes of classic $A B C$ model and aberrant mitochondrial gene expression $[45,48]$. These floral malformations which are linked to genetic background and cytoplasm types, 
results inefficient nectar production, impaired pollination, reduced female fertility, and consequently a drastic reduction in seed yield. The other alterations in flower phenotype and reproductive structures, such as aborted pollen, degenerative anthers, crooked or bent stigma, reduction in flower size, variation in filament size etc., are universal in autoplasmic and alloplasmic CMS systems of Brassica crops [6, 22-24, 49].In India, during the last three decades, a large number of CMS based breeding lines/material have been generated in Indian cauliflowers by repeated back crossing or somatic hybridization by exploiting various CMS sources. However, systematic characterization and identification of these floral malformations in CMS lines of the Indian cauliflowers have not been done so far.

Further, mitochondrial markers can be potentially be used to determine the CMS mitotypes and analyze genetic diversity in Indian cauliflower cytolines. Moreover, mitotype-specific SSRs can be reliably usedfordistinguishing normal cytolines from cytolines having varying degree of floral deformities in Indian cauliflowers.Identification of mt-SSRs and other mitochondria specific markersassociated with floral deformities will enable to screen out cauliflowers CMS lines with different types of floral abnormalities at an early stage. In the present investigation we have analysed a set of mitochondria specific SSRs across 76 cytoplasmic male sterile genotypes of Indian cauliflowers for distinguishing their cytotypes, assessing cytoplasmic genetic diversity and linking the polymorphism in these markers to CMS induced floral abnormalities.

\section{Results}

\section{Identification of cauliflower CMS types and genetic divergence}

The 76 CMS accessions (63 indigenously developed CMS lines and 13 CMS based hybrids) of cauliflower (Table 1) were screened using nineteen pairs of mitochondrial markers. These markers consist of 13 pairs of mitochondrial gene-specific primers: P1-P13 and six pairs ofmt-SSRs: P1-P13, designed based on the B. napusmitochondrial genome(Additional file 1: Table S1)[23, 38,50]. Among the 13 pairs of mitochondrial gene specific primers, 7 pairs specific to orf 138 were amplified. Although, they did not show any amplification for the control non CMSline (Fig 1).However, none of the primers governing pol, nap and tour cytoplasm generate any amplification. The 6 pairs of mitochondrial SSRs were amplified across the studied Indian cauliflower CMS lines. The amplification pattern of the gene based primers indicated that the cytoplasmtype of all the cytolines in Indian cauliflower was derived from Ogura CMS system;however, there was variation at nucleotide level among the studied CMS accessions. Two pairs of mt-SSRs, P15and P16specific toBnTR4 and orf125 genomic regions respectively, exhibited striking polymorphism among the CMS accessions. The amplicon size for the primer P15 and P16 varied between 200-280 bp and 410-470bp, respectively.

The PCA (Principal component analysis) and Neighbour joining (NJ) cluster analysis based on sequence of the mitochondrial amplicons obtained fromOguraCMS and in case of Brassica napusmitochondrialgenome based mtSSR markers was used to estimate the diversity in origin of male sterile cytoplasm in cauliflower accessions. In cluster analysis the CMS cauliflower lines could be categorized into three major distinct groups each with two subgroups and further sub-clusters in each sub-group (Fig. 2a, 2b). Broadly, six distinct sub-groups were determined based on the origin of their cytoplasm source (Fig. 2b). The six CMS lines (A38 to A43) including four CMS based hybrids CFH1522, Kimaya, Pahuja and Snowpearl remained in one single group; the other eight CMS accessions (A44 to A51) belonged to different group. Ten CMS accessions (A52 to A61) belonged to third group and other fifteen CMS lines (A62 to A76) including six CMS based hybrids (SM, Indam, KTCF-10A, Casper, Ponder, Brahma) formed fourth group. The nine CMS accessions (A29 to A37) represented in fifth group and rest of the twenty-eight 
CMS accessions (A1 to A28) including three CMS based hybrids of AcsenHyVeg private limited (HVCF-29, HVCF-18 and HVCF-16) formed the largest group (Fig. 2b).

\section{Sequence features of polymorphic amplicons}

The fragments amplified by primer P15 were of 251 bp for 46 CMS accessions under study and 220 bp for the remaining cytolines. The polymorphic amplicons of both these groups depicting 251 and 220 bp size were purified, cloned in pGEM-T vector and sequenced. The obtained sequences were subjected to multiple sequence alignment with each other and reference mitochondrial genome sequences of Brassicaceae crops exhibiting high degree of sequence similarity (Table 2). The accession numbers for the sequenced fragments were obtained from GenBank $\mathrm{NCBI}$ as described in the method section. The sequence analysis revealed that MN549523shared highly conserved region with MN549524 and high degree of similarity with other reference genomic regions of mitochondrial genome sequences of KU831325.1, KJ820683.1, AB627043.1, Sequence 3 P15, AP012988.1 and JF920286.1(Fig.3; Table 2).While, the MN549525 exhibited high degree of similarity with MN549526 and reference mitogenome sequences used in sequence alignment analysis such as Sequence 4 P15, AP018472.1 and AP012989.1 (Fig.3). The sequence alignment revealed single nucleotide polymorphism (SNP) at position $78(\mathrm{C} / \mathrm{T})$ and in addition, the deletion of 31 nucleotide between positions 78 and 110 for MN549525 and MN549526 (Fig. 3).

The amplicons generated by primer P16 were of size 420 bp in 42 CMS accessions under study and 471 bp in remaining. The obtained sequences were subjected to multiple sequence alignment with other mitogenome sequences of Brassicaceae crops available in NCBI database (Table 3). The sequence similarity analysis revealed that amplicons of MN549527 to MN549530shares a high degree of sequence similarity with each other and CMS related proteins in other Brassicaceae accessions AP018472.1, MG872827.1, JF920287.1, Seq6 P16, AP012990.1, AP012989.1 and AB694744.1 (Fig.4). Likewise, MN549531 exhibited highlyconserved regionwith Seq5 P16, KU831325.1 and KJ820683.1 (Fig. 4). The sequence alignment analysis revealed a deletion of size 51 bp between positions 371 to 423 in the exonic regions of ORFs for MN549527 to MN549530. While normal sequence without deletion was observed for MN549531.

\section{Cytoplasmic genetic variations and floral malformations}

We sought to investigate whether cytoplasmic genetic diversity associated with SNPs or InDels at loci BnTR4 and orf125(Fig. 3; Fig .4) has specifically impacted floral phenotypes of CMS lines. The polymorphism at these loci categorized the cytolines into two distinct groups (Fig. 2). It was evident that the cytolines exhibiting SNPs and deletions of 31 and 51 nucleotidesin the ORFs exonic region was associated with varying degree of floral abnormalities (Fig. 5; Table 4). The CMS lines with the absence of these InDels and SNPs identified by polymorphic markers had normal flower structure with no deformities which indicated the role ofcytoplasmic genetic variations in determining floral phenotypes. The major deformities recorded in the CMS lines were (i) adherence of functional stamens with style (ii) homeotic-like floral transformationpetaloidy condition of stamens (iii) partial petaloidy of functional stamens (iv) splitted style along with adherence of stamens (v) stigma hidden inside the petals (vi) splitted style along with exposed ovules (vii) unopened flower (viii) stamens adherence with style and crooked stigma (ix) partially opened flowers (x) absence of non-functional stamens (xi) fused flower (xii) curved functional stamens with crooked stigma and (xiii) absence of nectaries. Most of the CMS lines with none of the above floral deformities had normal female fertility and seed set(Fig. 5; Table 4).

\section{Analysis of ORFs and similarity of genes, phylogenetic relationships}


The open reading frame $(O R F)$ analysis revealed nucleotide deletion in the orf 125 coding region ofthe male sterile cytoplasm. The protein sequence analysis of polymorphic amplicons and reference mitotypes showed deleted nucleotide encoded 17 amino acids (Fig. 6). Therefore, polymorphism of P15 (BnTR4) and P16 (orf125) could be ascribed to SNPs or fragment insertion/deletion near the mt-SSR loci. The amino acid sequence analysis in the region of ORF depicted the polymorphic region amplifiedby P16 mt-SSR is located in the coding region of orf125 protein of B. oleracea (wild cabbage), B. juncea, B. rapassp. oleifera, Erucavesicariasubsp. sativa, B. oleracea var. capitataand $B$. oleracea var. botrytis (Additional file 1: Table S2)besides its location in $B$. carinataexonic region of orf108c. The protein sequence analysis revealed deletion of amino acids related to array of floral deformities withhigh degree of similarity with orf108c in B. carinata(Additional file 1: Table S2). The protein sequences devoid of deletion exhibited high similarity with orf125 in B. oleracea.

Polymorphism exhibited with with P15mt-SSR and mt-DNA sequences of other 9 Brassicaceae mitotypes were broadly grouped into two major groups (Fig.7a). The phylogenetic analysis revealed close affinity of cauliflower CMS lines,Ogu16A with Ogu12A and Ogu307-33A with Ogu33-1A. These cytoplasmic sources were clustered in one major group with one diploid accession of B. oleracea. This clustering in one group concurs withrapa/oleracea lineage propounded by Warwick and Black [51] based on chloroplast genome. Another group represented diploid $B$. oleracea var. botrytis, $B$. oleracea var. capitata, B. oleracea var. italica, Raphanus sativus var. kosenaand $B$. nigra. This grouping also corresponded to rapa/ oleracea lineage as proposed by Warwick and Black [51]except one species of nigralineage.Another group also confined to rapa/ oleracea lineage with the exception of one species of nigralineage [51]. Similarly, the polymorphic amplicons based on P16 mitochondrial marker and corresponding mtDNA sequences of ten Brassicaceae mitotypes were clustered two major groups (Fig.7b). The selected CMS sources, Ogu50A and Ogu17A were distantly placed from other CMS sources. OguHL-3A, Ogu12A and Ogu121-2A exhibited close affinity with each other and $B$. oleracea var. capitatabased on phylogenetic analysis. The CMS line Ogu50A depicted high affinity with KJ820683.1 (B.oleraceavar. botrytisL.)and Ogu17A showed high affinity with mitogenome of $B$. nigraand $R$. sativusvar. Kosena,and clusteredin one major group along with Raphanus sativus cv. Ms-gensuke, Ogu50A and B. oleracea var. botrytis (KJ820683.1). The black radish distantly placed itself from other members of its group.

\section{Effects of mito-nuclear genomic interactions on floral-nectar phenotypes in different nuclear backgrounds}

\section{Effect of cytonuclear interactions on floral qualitative traits}

In the present investigation we sought to analyze whether cytonuclear interactions specifically affected floral qualitative traits in the cytolines of Indian cauliflowers. Cauliflower cytolines along with their respective maintainers were characterized for five traitsnamelystyle shape, petal color, presence of floral nectaries, presence of viable pollen and type of ovary (Additional file 1: Table S3,Additional file 2: Fig.S1-S2).All the CMS lines had normal ovary and varied nectaries. None of the CMS line showed the presence of viable pollen grains and few lines were devoid of anther and pollen grains. The CMS accessions had straight to slightly curved or fully curved stigma. Yellow colored petals were predominant however white petals were recorded in Ogu33A, Ogu134-8A, Ogu13A, Ogu118-6A, OguKt-2-6A and Ogu118-2A.

\section{Cytonuclear interactions influencing floral reproductive whorls}


Comparative analysis for floral reproductive whorls and floral phenotypes of cauliflower cytolines and their respective male fertile counterparts was conducted to determine the effects of mito-nuclear co-adaptaion and disruption. The per se performance of several cytolines lines and their respective maintainers recorded significant variation for different floral phenotype (Additional file 1: Table S4, Additional file 2: Fig. S2).Petal length varied from $12.91 \mathrm{~mm}$ (Ogu76-4A) to $17.92 \mathrm{~mm}$ (Ogu2-6A). The longest petal was recorded in the CMS line Ogu2-6A followed by Ogu126-1A and Ogu310-8A. The petal width ranged from $4.18 \mathrm{~mm}$ (Ogu13-85-2A) to $7.83 \mathrm{~mm}$ (Ogu2-6A). The CMS line, Ogu2-6A followed by Ogu178-8A and Ogu33A-1301 had the widest petals. The ratio of petal length to petal width varied from 1.88 (Ogu33A-1301) to 3.82 (Ogu13-85-2A) and ratio was>2 except Ogu-13-01-5A, Ogu307$1 \mathrm{~A}$ and Ogu-13-01-33A.The considerable differences were also observed for sepal size,and the sepal length and width varied from $6.23 \mathrm{~mm}$ (Ogu15A) to $10.28 \mathrm{~mm}$ (Ogu2-6A) and $2.21 \mathrm{~mm}$ (Ogu13-85-2A) to $3.53 \mathrm{~mm}$ (Ogu115$8 \mathrm{~A}$ ), respectively. The ratio of sepal length to sepal width ranged from 2.19 (Ogu15A) to 3.88 (OguKt-2-1A). Like petal size, sepal size too was significantly reduced in the male sterile lines. The length of short (non-functional) and long (functional) filament ranged from $2.30 \mathrm{~mm}$ (Ogu16A) to $6.38 \mathrm{~mm}$ (Ogu310-8A) and $3.40 \mathrm{~mm}$ (33A-1301) to $7.52 \mathrm{~mm}$ (Ogu310-8A), respectively. The introgression of sterile cytoplasm resulted in elimination of non-functional filaments in 9CMS lines. Marked differences were also observed for stamen length, as the short stamen (nonfunctional) length varied from $3.41 \mathrm{~mm}$ (Ogu16A) to $8.13 \mathrm{~mm}$ (Ogu310-8A) and long stamen (functional) length from $4.79 \mathrm{~mm}$ (33A-1301) to $9.48 \mathrm{~mm}$ (Ogu2-6A). The ratio of functional (long stamen) to non-functional anthers (short stamen) was determined to detect any changes in CMS types and it varied from 1.03 (OguKt-2-1A) to 2.07 (Ogu77-4A) and it varied from 1.03 to 1.26 in maintainer lines. The 9 CMS lines viz. Ogu121-1A, Ogu122-1A, Ogu126-1A, OguKt-9-2A, OguKt-8-2A, Ogu118-3A, Ogu2A, Ogu3A, and Ogu118-2A were completely devoid of nonfunctional stamens. The significant differences were also observed in all the CMS lines for style length and it varied from $5.32 \mathrm{~mm}$ (Ogu14A) to $9.44 \mathrm{~mm}$ (Ogu16A). However, in the male fertile counterparts the style length varied from $6.33 \mathrm{~mm}$ to $10.86 \mathrm{~mm}$. These results clearly indicated the effect of cytonuclear genomic incompatibilities on reproductive whorls. Reduction in style length, stamen length and even absence of short stamens was also recorded in the cytolinesin different nuclear backgrounds. Generally, the position of style was higher than the stamens in majority of the cytolines except Ogu-Kt-2-1A, Ogu122-5A, Ogu118-4A, Ogu33-1A, Ogu33A, Ogu77-4A, OguKt-9-2A, Ogu3A and Ogu14A (Additional file 1: Table S4). Introgression of ogura cytoplasm invariably reduced the stamen length in call Indian cauliflower lines. The relative position of stamens and stigma was determined by estimating the ratio between functional stamens and style length. The ratio varied from 0.62 (33A-1301) to 1.30 (Ogu14A) in CMS lines and 0.98 to 1.46 in male fertile counterparts.

\section{Impact of cytonuclear interactions on nectar production}

Comparative nectar quantity in the cytolines and their respective male fertile maintainers was conducted to determine nuclear-cytoplasmic interaction for this trait. Significant variation was observed in the cytolines lines for nectar quantity (Table 5). The nectar quantity varied from $0.28 \mu \mathrm{l}$ (Ogu15A) to $5.69 \mu \mathrm{l}$ (Ogu1-8A) in the CMS lines, while in the male fertile counterpart the nectar quantity varied from $0.60 \mu \mathrm{l}$ to $13.94 \mu \mathrm{l}$. The highest quantity of nectar was found in the CMS line, Ogu1-8A followed by Ogu308-6A and Ogu2-6A. The results (Table 5) revealed significant reduction in the nectar quantity of cytolinesas compared to their respective male fertile counterparts.

\section{Cluster analysis}

The CMS lines were grouped into different clusters based on floral reproductive whorls and phenotypic traits and 2 major clusters ( $\mathrm{Cl}$ and $\mathrm{CII}$ ) formed with two sub-clusters in cluster II (Fig.8). The sub-clusters (C-IIA and C-IIB) in the cluster-II were further grouped into sub-clusters C-IIA-1, C-IIA-2 and C-IIB-1, C-IIB-2. Majority of CMS lines were 
grouped into cluster II and cluster I had only 9 CMS lines. All the CMS accessions with the absence of non functional stamens remained in cluster-I. The $6 \mathrm{CMS}$ lines with the functional stamens of length $8.5 \mathrm{~mm}$ to 9.48 $\mathrm{mm}$ remained in the sub-cluster C-IIA-1. The nine CMS accessions grouped into sub-cluster C-IIA-2 with nonfunctional filament length 3.1-3.8 $\mathrm{mm}$ and majority of the CMS lines in this cluster had sepal width $<2.45 \mathrm{~mm}$. The sub-cluster C-IIB-1a contained five CMS lines with petal length $<14.5 \mathrm{~mm}$, style length $6.28-6.6 \mathrm{~mm}$ and functional stamen length of 6.49-6.61 mm . The sub-cluster C-IIB-1b had ten CMS lines and majority of them (60\%) have petal length 15-17 mm and sepal width 2.9-3.4 mm. The sub-cluster C-IIB-2a comprised of eight CMS lines and majority of them had sepal length $>8.7 \mathrm{~mm}$ (i.e. 8.7-9.8 $\mathrm{mm}$ ). The remaining thirteen CMS lines were clustered into sub-cluster C-IIB-2b with petal length of $>13 \mathrm{~mm}$ to $<15 \mathrm{~mm}$ in majority of the lines.

\section{Discussion}

\section{Mitochondrial markers in identifying $B$. oleracea CMS lines with floral deformities}

The CMS phenotype is a common feature in higher plants controlled by mt-DNA and widely used to facilitate hybrid development in Brassica vegetables [11, 13, and 23]. The propensity to frequent recombination, mt-DNA rearrangements and encoding of numerous genes makes plant mitogenome more complex relative to their metazoan counterpart.In this context, the role of mitochondrial markers in quick identification and differentiation of different CMS types has been reported earlier in other members of Brassicaceae [23, 37-40, 52]. We are reporting the usefulness of mitochondria specific markers in selecting CMS lines with normal flower structure and extent of mitogenome diversity for the first time in Indian cauliflower. In this study mt-DNA specific primers associated with different CMS genes, orf138, orf222, orf224, orf222-224, orf263, atp6-orf224 and mt-SSRs were utilized. The results revealed that all the cytolines of Indian cauliflowerpossessed orf138 related fragment specific to Ogura CMS eatablishing wide use of Ogura cytoplasm in the development of CMS [10-11, 23, 37, 53-55]. Therefore, it is urgently needed to diversify the source of the CMS in Indian cauliflowers to avoid any imminent threat of epidemicwhich may collapse the entire hybrid seed industry of Brassica oleracea vegetables. The male sterile cytoplasm available in other Brassicas like Trachystomaballii, Diplotaxiscatholica, D. berthaultii, B. tournefortii, Moricandia arvensis, Erucasativacouldbe utilized to diversify CMS system in Indian cauliflowers. However, the polymorphic mt-SSRs loci indicated the presence of cytoplasmic genetic variation among OguraCMS based male sterile genetic stock of Indian cauliflowers. The PCA and NJ cluster analysis based on combined analysis of mt-DNA specific and mt-SSR markers classified the 76 cytolines into six different groups (Fig.2b).

The polymorphic amplicons generated with primer P15 were of size between 220 to $280 \mathrm{bp}$, while for P16 of 410 $470 \mathrm{bp}$ size. The length of polymorphic products of A13 to A17, A24 to A27, A29 to A37, A69, A73, A2, A4-A5, and A52-A58 were identical to as reported in B.oleraceavar. capitata[38], which can differentiate OguCMSHY, OguCMSR 1 . ${ }_{2}$ (420bp) from polCMS and $\mathrm{OguCMSR}_{3}(471 \mathrm{bp})$. Similar findings were reported for 5 CMS lines of broccoli [23]. Therefore, the original source of OguCMS in the studied cauliflower cytolines could have come from $O g u C M S R_{1-2}$ and OguCMSHY. The sequence analysis revealed that SNPs and insertion/deletions could explain the cytoplasmic genetic variations among cytolines of Indian cauliflowers. Polymorphic amplicons targeting orf 125 coding regions of mitochondrial genome demonstrated a deletion of 51 nucleotides in the CMS lines with varied floral deformities. Similarly, the deformed CMS lines had a deletion of 31 nucleotides in the coding region of BnTR4. Wang et al. [38] successfully reported the use of chloroplast (cpSSRs) and mitochondrial (mt-SSRs) primers in demonstrating the polymorphism in alloplasmic CMS lines of cabbage. Shu et al $[23,37]$ demonstrated the role of organelle SSRs, mtDNA specific and mt-SSR markers in distinguishing different CMS types, differentiating CMS lines with carpelloid stamens in broccoli. Cytoplasmic genetic variations associated with deletions of $31 / 51$ nucleotides in the ORFS 
exonic region demonstrated that insertions/deletions of nucleotides can explain the wide range of floral abnormalities in the CMS lines of Indian cauliflowers.

Mito-nuclear genomic incompatibilities and introgression of alien cytoplasm have been reported to display complex floral structure variations in auto-and alloplasmic CMS lines of Brasssicacrops. The flowering regulation in higher plants is highly complex process controlled by interactions of genes or genes $\times$ environment. MADS-box genes are crucial player in plants for vegetative and reproductive growth development $[44-48,56]$. The identity and development of each floral reproductive whorl is determined by varying combinations of genes of classical flowering $A B C D E$ model [56]. It is well documented that loss of function, mutations or insertions/deletions in MADSbox transcription factors such as APETALA2, APETALA3 or PISTILLATA, AGAMOUS, AGL 11, SEP1, SEP2, SEP3, SEP4, SHP2, SHP2 etc causes varying degree of floral malformations [44-48, 56].Different types of floral abnormalities observed in the cauliflower cytolines (Fig. 5) such as homeotic- like modification of stamens to petal like structures (petaloidy), adherence of functional stamens to style, partially opened flowers, splitted style with exposed ovule, splitted style, absence of nectaries, rudimentary nectaries and fused flowers could be explained by absence of amino acids causing dysfunction of one of MADS-box genes. Further, the dosage imbalance of class $B$ and class $\mathrm{C}$ genes of flowering model, aberrant mitochondrial gene expression results homeotic-like floral deformitiesobserved in the present investigation [45,48]. Previously, the role of deletions of nucleotide in the ORFS coding region of broccoli cytolines was suggested to be associated withcarpelloid stamen phenotype [23, 37], however, their role in cause an array of floral deformities is not reported. Identification of these specific deletion associated with several floral deformities would be instrumental in selection of desirable CMS types for hybrid breeding and will enhance the understanding about evolutionary relationships in Brassicas. Analysis of ORFS, similarity of genes and protein sequence revealed that polymorphic loci were located at exonic regions of orf 125 and orf $108 \mathrm{c}$ of mitochondrial genomes of Brassicaceae species. It is quite likely that orf125 and orf108c mitochondrial genes are playing pivotal role in development of flower organs. The floral abnormalities which are associated with aberrant mitochondrial gene expression, mutation in mitochondrial genomes, cytoplasmic-nuclear conflict, cytoplasm types and genetic backgrounds, renders scanty nectar production, impaired pollination and affects female fertility $[22,37,43,57]$. These characteristics consequently results poor seed yield. Identification and roughing out undesirable cytolines in the initial stage of breeding programme will save huge time efforts in developing CMS lines for their successful use in hybrid development.

In the present investigation and our earlier reports $[43,58]$ we observed floral abnormalities in CMS lines in successive nuclear backgrounds. Initially the expression of floral deformities may be weak or incomplete because of partial substitution of nuclear genome. The exact expressions were observed only after complete nuclear substitution. The identification of specific insertion/deletion and SNPs associated with floral abnormalities in the initial stage of back-cross introgression will help the breeders to use only those CMS types which will later results in normal flower structures. The polymorphism in the cytolines of varying nuclear backgrounds carrying identical cytoplasmsuggests possiblepaternal leakage in certain cases. However, further investigation is needed to establish the role of the paternal genome in inheritance of the mitochondrial genome controlled male sterility in $B$. oleracea lines. The proclivity of plant mitochondrial genome to frequent recombination, genomic rearrangements and rapid structural evolution leading to heteroplasmy results in polymorphism in cauliflower cytoplasmic sources [59-60]. Predominantly, the uni-parental, which is maternal inheritance of chloroplast and mitochondrial genome is reported in most of the angiosperms $[2,61]$ including Brassica crops such as broccoli, cabbage and cauliflower [37, 62-63]. Recently, the paternal $[60,64-66]$ and biparental [67-68] inheritance of mitogenome is also reported. Therefore, the findings of the present study need to be analyzed further to detect any possible paternal inheritance of mitochondrial genome. 


\section{Nucleo-mitochondrial interactions influencing floral-nectar phenotypes}

Pollinators play an important role in hybrid breeding of Brassicas and pollinator visit is determined by flower phenotype like size, color and form [57].Usually, the large flower size is positively linked with more numbers of pollinator visits, as large floral organ size is generally assumed to contain more nectar [57, 69-71]. Floral nectar is the primary reward besides pollen, floral oils, resins and scents, offered to pollinators and their proportionate ratio is vital in determining plant-pollinator interactions [71]. Floral organ size, morphology, proper development of nectaries, efficient nectar production, fruiting featuresand pollinator attracting ability are considered as potent indexes to evaluate cytolines [57]. The cytoplasmic effects on floral phenotypes are well documented in Brassicas which are manifested through cyto-nuclear allelic interactions. The role of additive mito-nuclear genetic effects on altering floral phenotypes is rare, while epistatic cytonuclear genetic effects are larger in magnitude [72-73]. In the present investigation, the effects of cytonuclear interactions on floral qualitative traits were insignificant in different nuclear backgrounds (Additional file 1: Table S3; Fig. S1-S2). However, varying degree of cytoplasmic effects on floral reproductive whorls, floral size, structure and other floral-nectar phenotypes were observed over the successive backcross generations in the development of cauliflower cytolines (Additional file 1: Table S4). The introgression of sterile cytoplasm significantly reduced the flower size in the form of reduction in petal length, petal width, and sepal length across the nuclear background series. The other predominant type of structural changes in reproductive whorlswere flowers devoid of non-functional stamens, alteration in style length, reduction in functional stamens length, modification in position of style and anthers (style position was higher than anthers across the nuclear background series with a few exceptions) and inefficient nectar production. The genetic conflict of sterile cytoplasm- nuclear genome of B.oleraceavar. botrytis could explain the floral deformities [2, 6, 11]. In Arabidopsis, the role of cytonuclear epistasis on various adaptive traits is suggested [73].Singh and Srivastava [74] observed the narrowing of petals, reduction of filament length, increase in style length in the $B$. junceamale sterile lines with the introgression of ogura, tournefortii, trachystomaand siifoliawild cytoplasm. They also obtained the erratic results with the oguracytoplasm in the different nuclear backgrounds because ofmito-nuclear epistasis. Although, it is also suggested that rigorous recurrent manual or honey bee- mediated selection during backcross breeding cycles could reduce floral deformities to a limited extent $[43,75]$. However, it is not possible to ameliorate these deformities through conventional back-crossing and different selection strategies.

Understanding the molecular mechanisms and pathways of cytoplasmic male sterility in cauliflower associated with floral abnormalities along with determining the paternal leakage (if any) need further in depth investigation. Identified molecular markers associated with different kind of floral deformities will facilitate the selection of CMS lines with normal flower structure at the initial stage of breeding.

\section{Methods}

\section{Plant materials and nucleic acid isolation}

The basic plant material consisted of $76 \mathrm{CMS}$ accessions of cauliflower with different nuclear backgrounds, developed after more than nine generations of backcrossing (Table 1). Among the 76 CMS lines, 71 lines were developed at ICAR-Indian Agricultural Research Institute, Regional Station, Katrain, Kullu, HP-175129, India through back-crosss introgression. Four CMS based $\mathrm{F}_{1}$ hybrids, Casper, KTCF-10A, Ponder and SM were obtained from by RijKZ waan private limited and one $\mathrm{CMS}_{\text {based }} \mathrm{F}_{1}$ hybrid, Indam was obtained from Indo Americal Hybrid Seeds company. (Table 1). In addition, one non CMS inbred line of cauliflower 'Sel-27' was used as a control the CMS accessions were grown in pro-trays under glasshouse conditions of Baragram Experimental Farm of ICAR-Indian 
Agricultural Research Institute (IARI), Regional Station, Katrain, Kullu Valley, Himachal Pradesh, India for extraction of DNA. DNA was isolated from fully expanding leaves $(100 \mathrm{mg})$ from 25-30 days old seedlings using cetyltrimethyl ammonium bromide (CTAB) method with minor modifications [76].The genomic DNA samples were adjusted to 25$50 \mathrm{ng} \mathrm{DNA} / \mu \mathrm{l}$ and were stored at $-80^{\circ} \mathrm{C}$ till use.

\section{PCR amplification}

Nineteen pairs of mitochondrial markers were used to detectnucleotide diversity among male sterile mitotypes of Indian cauliflowers(Additional file 1: Table S1) [23]. One pair of primers (P1) was specific to orf138 determining Ogura CMS, two pairs of primers specific to orf222 (P2 and P3), one pair specific to orf222-orf224 (P4), then orf224 (P5), atp6-orf224 (P6) and orf263 (P7). The six pairs of primers (P8-P13) were based on orf138 related genomic sequences and other six pairs (P14-P19) were mitochondrial simple sequence repeat markers (mt-SSRs) [23].The PCR amplifications were carried out in a reaction mixture consisted of $2 \mu$ l of genomic DNA template $(50 \mathrm{ng}), 1 \mu \mathrm{l}$ of each forward and reverse primers, $12.50 \mu \mathrm{l}$ of 2xPCR Green master mix (GoTaq DNA polymerase; Promega, USA) and $8.50 \mu \mathrm{l}$ nuclease free water. The Eppendorf Mastercycler Nexus GSX1 was used for PCR amplification. Amplification was done following PCR cycling programme : an initial denaturation of $95^{\circ} \mathrm{C}$ for 5 min, then 35 cycles of denaturation at $95^{\circ} \mathrm{C}$ for $30 \mathrm{~s}$, annealing of primers at suitable temperature for $30 \mathrm{~s}$ and extension at $72{ }^{\circ} \mathrm{C}$ for $1 \mathrm{~min}$, then a final extension of $72^{\circ} \mathrm{C}$ for $7 \mathrm{~min}$. The amplification by each polymorphic locus was repeated three times for the confirmation and the PCR products were separated on $3 \%$ agarose gel electrophoresis in 1X TBE buffer $(\mathrm{pH} 8.0)$ at $100 \mathrm{~mA}$ voltage for $120 \mathrm{~min}$. Ethidium bromide $(\mathrm{EtBr})$ of $0.5 \mathrm{mg} / \mathrm{ml}$ was used for gel staining and gel pictures were captured using digital gel documentation unit (BioSpectrum ${ }^{\circledR}$ Imaging System ${ }^{\mathrm{TM}}, \mathrm{UK}$ ). The determination of fragment sizes was done using PromegaTM 100 bp DNA step ladder.

\section{Cluster analysis based on mitochondrial markers}

To categorize the CMS accessions into distinct groups, the molecular data generated by combining the two types of analytical methods (mitochondrial DNA-specific markers and B. napusbased mt-SSRs) was subjected to cluster analysis via neighbor-joining (NJ) unweighted pair group method with arithmetic mean (UPGMA) using DARwin v6.0.017 [77]. The simple matching (SM) coefficient was computed to calculated genetic distance.

\section{Sequence analysis and genome annotation}

The PCR products were purified using Wizard® SV Gel and PCR Clean-Up System (Promega). For each of the polymorphic loci the representative purified PCR products were cloned into $p G E M B-T$ Easy vector system (Promega Corporation, USA) following the supplier's guidelines. The products were transformed into $\mathrm{E}$. coli ( $\mathrm{DH} 5 \mathrm{a})$ competent cells. The positive clones were confirmed by colony PCR and restriction digestion. The five positive clones for each of the selected polymorphic fragments weresubjected to Sanger Dideoxy sequencing (Eurofins Genomics India Pvt., Ltd.). The per cent sequence identity and similarity analysis was carried out with NCBI (National Center for Biotechnology Information) web based BLAST service (https://blast.ncbi.nlm.nih.gov/) [78] for the comparative analysis of obtained sequences with available relevant mitochondrial genome sequences in Brassicaceae. The Sanger sequences obtained were assembled and subjected to multiple sequence alignment with reference mitochondrial genomes to determine any variation at nucleotide level using SeqMan Pro tool of DNASTAR version 15.3 (Lasergene Inc. Madison, WI, USA, https://www.dnastar.com/). The phylogenetic tree was constructed with MEGA X software [79] based on different datasets of polymorphic primers. NCBI ORF finder (https://www.ncbi.nlm.nih.gov/orffinder/)was used to determine ORF numbers in the representative DNA sequence of polymorphic loci and to screen hypothetical protein translations. To verify predicted proteins, NCBI BLASTP or 
SMART BLAST [78] was used. The amino acid multiple sequence alignment was performed using CLUSTAL Omega programme [80].

\section{Accession numbers of selected polymorphic amplicons}

The sequences of selected representative polymorphic amplicons of Ogu307-33A, Ogu33-1A, Ogu16A, Ogu12A, Ogu12A-orf125, Ogu121-2A, Ogu-HL-3A, Ogu17A and Ogu50A have been submitted to the GenBank nucleotide sequence database of NCBI under the accession numbers of MN549523, MN549524, MN549525, MN549526, MN549527, MN549528, MN549529, MN549530 and MN549531, respectively.

\section{Impact of mito-nuclear interactions on floral-nectar phenotype}

The field study was carried out at Baragram Experimental Farm of ICAR-IARI, Regional Station, Katrain, Himachal Pradesh, India, situated along the river Beas. The recommended package of practices, suggested for growing a healthy crop at the Baragram Experimental Farm, were followed for better agronomic and phenotypic expression of crop [15]. To determine the cytoplasmic effect inducing alteration in floral reproductive traits, a comparative phenotypic analysis of a set of $60 \mathrm{CMS}$ lines (A line) of snowball group of Indian cauliflower along with their respective male fertile counterparts (B line)was done based on important floral morpho-physiological traits viz. (i) petal color (ii) shape of style (iii) presence of floral nectaries (iv) presence of viable pollen (v) type of ovary (vi) petal size : petal length $(\mathrm{mm})$ and petal width $(\mathrm{mm})$ (vii) ratio of petal length to petal width (viii) sepal size : sepal length $(\mathrm{mm})$ and sepal width $(\mathrm{mm})$ (ix) ratio of sepal length to sepal width (x) short filament length (mm) (xi) long filament length $(\mathrm{mm})$ (xii) short stamen length $(\mathrm{mm})$ (xiii) long stamen length $(\mathrm{mm})(x i v)$ style length $(\mathrm{mm})(\mathrm{xv})$ ratio of stamen to style (xvi) ratio of long stamen to short stamen and (xvii) nectar quantity $(\mu \mathrm{l})[22,43,74,81-82]$. The petal length to petal width ratio was estimated to determine changes in petal size. The long stamen to style ratio was determined to estimate relative position of stigma to stamen. The long to short stamen ratio was estimated to determine the effect of cytoplasm on stamen length [74]. The presence or absence of pollen grains was determined on the basis of visual observation and pollen viability was tested by staining with $2 \%$ acetocarmine [74]. All the CMS lines and their respective maintainers were evaluated for different floral traits in Randomized Block Design (RBD) design with three replications to quantify the modifications in flower reproductive features because of sterile cytoplasm introgression. Observations were recorded from 12 flowers per genotype (4 flowers from 3 plants) in each replication. The CMS accessions (A lines) were compared with their respective $B$ lines for detection of floral abnormalities (e.g. pistillody, carpelloid stamen, petaloid stames, splitted style, partially opened flowers, fused flowers, absence of nectaries etc.). Floral nectar is an important trait for comprehending the plant-pollinator mutualisms. For the analysis of effect of nuclear-genomic conflict on nectar production, the quantification of nectar production was done from CMS accessions and their respective maintainers. The data was taken from 10 flowers of each genotype during early morning hours with graduated capillary of $10 \mu$ l. The average data was used for further statistical analysis.

\section{Statistical analysis for floral-nectar traits}

All the CMS lines were clustered into different groups based on cluster analysis and dendrogram construction based on Euclidean distance was done with the PCA and neighbor joining (NJ) UPGMA method using DARwin software version 6.0.017 [77]. For testing the reliability of NJ dendrogram, a bootstrap value of 1000 replicates was used. To compare the A and B lines, average of CMS lines and their male fertile counterparts (maintainers) for different floral traits was compared using paired t-test by subjecting the data to ' $R$ ' statistical software. 


\section{Declarations}

\section{Ethics approval and consent to participate}

Not applicable

\section{Consent for publication}

Not applicable

\section{Availability of data and materials}

All the data sets generated and analysed during this investigation are presented in this published research article and its supplementary additional information files.

\section{Competing interests}

All the authors declare that they have no competing interests with respect to any aspect of this research.

\section{Funding}

Financial support was provided by the NAHEP/CAAST research grant by Indian Council of Agricultural Research. Funding was provided to Dr. Saurabh Singh for this PhD research programme. ICAR-Indian Agriculrural Research Institute, provided Senior Research Fellowship (SRF) during his PhD programme.

\section{Authors' Contribution}

SSD and RB conceived and designed the study. SS and SSD performed the experiment. SS did the data recording and lab experiments with the input from KS, HG, and KK. SS and SSD analyzed the data. AP helped in recording of data related to the reproductive structure of the CMS lines. RK, SSD, RB monitored and contributed the materials. SS performed the sequencing and other molecular analysis. SS and SSD wrote the original draft manuscript. SSD, TKB, RK and RCB edited thefinal manuscript. All the authors read and approved the final manuscript.

\section{Acknowledgements}

Financial support was provided by the NAHEP/CAAST research grant by Indian Council of Agricultural Research. First author is thankful to ICAR-IARI for providing senior scholarship during the Ph.D. programme. Authors are also thankful to Dr. Amolkumar U. Solanki, ICAR-National Institute for Plant Biotechnology, New Delhi, India for timely help during analysis of sequence data and interpretation of sequencing results.

\section{Authors' information}

${ }^{1}$ Division of Vegetable Science, ICAR-Indian Agricultural Research Institute, New Delhi, India-110012 (horticulturesaurabh@gmail.com) (*shyam.iari@gmail.com);2Division of Floriculture and Landscaping, ICAR-Indian Agricultural Research Institute, New Delhi, India-110012; ${ }^{3}$ ICAR-Indian Agricultural Research Institute, Regional Station, Katrain, Kullu Valley, H.P., India-175129; ${ }^{4}$ ICAR-National Institute for Plant Biotechnology, Pusa Campus, New Delhi, India-110012

\section{References}


1. Welchen E, Garcia L, Mansilla N, Gonzalez DH. Coordination of plant mitochondrial biogenesis: keeping pace with cellular requirements. Front Plant Sci. 2014; 4: 551. doi: 10.3389/fpls.2013.00551.

2. Chen Z, Zhao N, Li S, Grover CE, Nie H, Wendel JF, Hua J. Plant mitochondrial genome evolution and Cytoplasmic male sterility. Crit Rev Plant Sci. 2017; 36: 55-69. doi: 1080/07352689.2017.1327762.

3. Shu J, Zhang L, Liu Y, Li Z, Fang Z, Yang L, et al. Normal and abortive buds transcriptomic profiling of Broccoli ogucytoplasmic male sterile line and its maintainer. Int J Mol Sci. 2018; 19: 2501. doi: 3390/ijms19092501.

4. Christensen A. Plant mitochondrial genome evolution can be explained by DNA repair mechanisms. Genome Biol Evol. 2013; 5: 1079-1086.

5. Horn R, Gupta KJ, Colombo N. Mitochondrion role in molecular basis of cytoplasmic male sterility. Mitochondrion. 2014; 19: 198-205.

6. Chase CD. Cytoplasmic male sterility: a window to the world of plant mitochondrial-nuclear interactions. Trends Genet. 2007; 23: 81-90.

7. Sloan DB. One ring to rile them all? Genome sequence provides new insights into the 'master circle' model of plant mitochondrial DNA structure. New Phytol. 2013; 200: 978-985. doi: 1111/nph.12395.

8. Gualberto JM, Mileshina D, Wallet C, Niazi AK, Weber-Lotfi F, Dietrich A. The plant mitochondrial genome: dynamics and maintenance. Biochimie. 2014; 100: 107-120.

9. Gualberto JM, Kuhn K. DNA-binding proteins in plant mitochondria: implications for transcription. Mitochondrion. 2014; 19: 323-328. doi: 1016/j.mito.2014.02.004.

10. Tanaka Y, Tsuda M, Yasumoto K, Yamagishi H, Terachi T. A complete mitochondrial genome sequence of Ogura-type male-sterile cytoplasm and its comparative analysis with that of normal cytoplasm in radish (Raphanus sativus). BMC Genomics. 2012; 13: 352. doi: 10.1186/1471-2164-13-352

11. Singh S, Dey SS, Bhatia R, Kumar R, Behera TK. Current understanding of male sterility systems in vegetable Brassicas and their exploitation in hybrid breeding. Plant Reprod. 2019a; 32: 231-256. doi: 1007/s00497-01900371-y.

12. Bohra A, Jha UC, Adhimoolam P, Bisht D, Singh NP. Cytoplasmic male sterility (CMS) in hybrid breeding in field crops. Plant Cell Rep. 2016; 35: 967-993. doi: 10.1007/s00299-016-1949-3.

13. Singh S, Bhatia R, Kumar R, Sharma K, Dash S, Dey SS. Cytoplasmic male sterile and doubled haploid lines with desirable combining ability enhances the concentration of important antioxidant attributes in Brassica oleracea. 2018a; 214: 207. doi: 10.1007/s10681-018-2291-3.

14. Singh S, Dey SS, Kumar R, Bhatia R, Ghemeray H, Behera TK. Genetic analysis and interaction among CUPRAC, FRAP, phytochemical and phenotypic traits in cauliflower (Brassica oleracea botrytis L.). Int J Chem Stud. 2019b; 7: 1484-1494.

15. Singh S Dey SS, Bhatia R, Kumar R, Sharma K, Behera TK. Heterosis and combining ability in cytoplasmic male sterile and doubled haploid based Brassica oleraceaprogenies and prediction of heterosis using microsatellites. PLoS ONE. 2019c; 14(8): e0210772. https://doi.org/10.1371/journal.pone.0210772.

16. Thakur P, Vidyasagar, Singh S. Evaluation of cytoplasmic male sterile (CMS) progenies and maintainer lines for yield and horticultural traits in cabbage (Brassica oleracea capitata L.). SABRAO J Breed Genet.2015; 47: 2939.

17. Dey SS, Sharma SR, Bhatia R, Parkash C, Barwal RN. Superior CMS (Ogura) lines with better combining ability improve yield and maturity in cauliflower (Brassica oleracea botrytis). Euphytica. 2011a; 182: 187. doi: 10.1007/s10681-011-0425-y. 
18. Singh S, Singh R, Thakur P, Kumar R. Phytochemicals, functionality and breeding for enrichment of cole vegetables (Brassica oleracea ). In:Petropoulos SA, Ferreira ICFR, Barros L, editors. Phytochemicals in Vegetables: A Valuable Sourcce of Bioactive Compounds. Bentham Science Publishers, UAE; 2018b. p. 256295.

19. Sehgal N, Singh S. Progress on deciphering the molecular aspects of cell-to-cell communication in Brassicaselfincompatibility response. 3Biotech. 2018; 8: 347. doi: 1007/s13205-018-1372-2.

20. Cardi T, Earle ED. Production of new CMS Brassica oleraaceaby transfer of 'Anand' cytoplasm from rapathrough protoplast fusion. Theor Appl Genet. 1997; 94: 204-212. doi: 10.1007/s001220050401.

21. Yamagishi H, Bhat SR. Cytoplasmic male sterility in Brassicaceae crops. Breed Sci.2014; 64: 38-47. doi: $1270 /$ jsbbs.64.38.

22. Kang L, Li P, Wang A, Ge X, Li Z. A novel cytoplasmic male sterility in Brassica napus(inapCMS) with carpelloid stamens via protoplast fusion with Chinese woad. Front Plant Sci. 2017; 8: 529. doi: 10.3389/fpls.2017.00529.

23. Shu J, Liu Y, Li Z, Zhang L, Fang Z, Yang L, Zhuang M, Zhang Y, Lv H. Detection of the diversity of cytoplasmic male sterility sources in broccoli (Brassica oleracea italica) using mitochondrial markers. Front Plant Sci. 2016; 7: 927. doi: $10.3389 / f p l s .2016 .00927$.

24. Dey SS, Bhatia R, Sharma SR, Sharma K, Parkash C, Kumar R. Population dynamics in introgression of wild male sterile cytoplasm into Brassica oleracea: a small population based breeding modelr. Sci Hortic. 2018; 232: 231-239. doi: 1016/j.scienta.2018.01.008.

25. Ogura H. Studies on the new male sterility in Japanese radish, with special references to the utilization of thissterility towards the practical raising of hybrid seeds. Mem Fac Agric Kagoshima Univ. 1968; 6: 39-78.

26. Handa H, Gualberto JM, Grienenberger JM. Characterization of mitochondrial orfBgene and its derivative, orf224, a chimeric open reading frame specific to one mitochondrial genome of the "Polima" malesterile cytoplasm in rapeseed (Brassica napus). Curr. Genet. 1995; 28: 546-552. doi: 10.1007/BF00518167.

27. Iwabuchi M, Koizuka N, Fujimoto H, Sakai T, Imamura J. Identification and expression of the kosena radish (Raphanus sativus Kosena) homologue of the Ogura radish CMS-associated gene, orf138. Plant Mol Biol. 1999; 39: 183-188.

28. Shinada T, Kikucho Y, Fujimoto R, Kishitani S. (An alloplasmic male-sterile line of Brassica oleracea harboring the mitochondria from Diplotaxismuralisexpresses a novel chimeric open reading frame, orf72. Plant Cell Physiol.2006; 47: 549-555.

29. L'Homme Y, Stahl RJ, Li XQ, Hameed A, Brown GG. Brassica nap cytoplasmic male sterility is associated with expression of a mtDNA region containing achimeric gene similar to the pol CMS associated orf224 Curr Genet. 1997; 31: 325-335.

30. Wang HM, Ketela T, Keller WA, Gleddie SC, Brown GG. Genetic correlation of the orf224/atp6 gene region withPolima CMS in Brassica somatic hybrids. Plant Mol Biol. 1995; 27: 801-807.

31. Heng S, Gao J, Wei C, Chen F, Li X, Wen J, et al. Transcript levels of orf288are associated with the hau cytoplasmic male sterility system and altered nuclear gene expression in Brassica juncea. J Exp Bot. 2018; 69: 455-466. doi: 1093/jxb/erx443.

32. Landgren M, Zetterstrand M, Sundberg E, Glimelius K. Alloplasmic male-sterile Brassica lines containing tournefortiimitochondria express an ORF 3' of the atp6 gene and a 32 kDa protein. Plant Mol Biol. 1996; 32: 879-890. 
33. Yang JH, Liu XY, Yang XD, Zhang MF. Mitochondrially- targeted expression of a cytoplasmic male sterility associated orf220 gene causes male sterility in Brassica juncea. BMC Plant Biol. 2010; 10: 231.doi:

10.1186/1471-2229- 10-231.

34. Chang CT, Kakihara F, Hondo K, Kato M. The cytoplasm effect comparison between Brassica napusand Brassica carinataon floral characteristics of Brassica oleracea. Plant Breed. 2011; 130: 73-79.

35. Yamagishi $\mathrm{H}$, Tanaka Y, Terachi T. Complete mitochondrial genome sequence of black mustard (Brassica nigra; BB) and comparison with Brassica oleracea(CC) and Brassica carinata (BBCC). Genome. 2014; 57: 577-582. doi: 1139/gen-2014-0165.

36. Heng S, Wei C, Jing B, Wan Z, Wen J, Yi B, Ma C, Tu J, Fu T, Shen J. Comparative analysis of mitochondrial genomes between the haucytoplasmic male sterility (CMS) line and its iso-nuclear maintainer line in Brassica junceato reveal the origin of the CMS associated gene orf288. BMC Genomics. 2014; 15: 322. doi: 1186/14712164-15-322.

37. Shu J, Liu Y, Li Z, Zhang L, Zhang L, Fang Z, et al. Organelle simple sequence repeat markers help to distinguish carpelloid stamen and normal cytoplasmic male sterile sources in broccoli. PLOS ONE. 2015; 10(9): e0138750. doi: $1371 /$ journal.pone.0138750.

38. Wang Q, Zhang Y, Fang Z, Liu Y, Yang L, Zhuang M. Chloroplast and mitochondrial SSR help to distinguish allocytoplasmic male sterile types in cabbage (Brassica oleracea var. capitata). Mol Breed. 2012; 30: 709-716. doi: 10.1007/s11032-011-9656-9.

39. Zamani-Nour S, Clemens R, Mollers C. Cytoplasmic diversity of Brassica napus, Brassica oleracea L. and Brassica rapa L. as determined by chloroplast microsatellite markers. Genet Resour Crop Evol. 2013; 60: 953965.

40. Zhang RJ, Hu SW, Yan JQ, Sun GL. Cytoplasmic diversity in Brassica rapa investigated by mitochondrial markers. Genet Resour Crop Evol. 2013; 60: 967-974.

41. Heng S, Shi D, Hu Z, Huang T, Li J, Liu L, Xia C, Yuan Z, Fu T, Wan Z. Characterization and classificationof one new cytoplasmic male sterility (CMS) line based on morphological, cytological and molecular markers in nonheading Chinese cabbage (Brassica rapa). Plant Cell Rep. 2015; 34: 1529-1537. doi: 10.1007/s00299-0151804-y.

42. Yu X, Liu Y, Lv Y, Liu Z, Chen Z, Lu G, Cao J. Development of molecular markers specific to petaloid-type cytoplasmic male sterility in tuber mustard (Brassica junceatumidaTsen et Lee). Mol Biol Rep.2014; 41: 769778. doi: 10.1007/s11033-013-2916-5.

43. Dey SS, Bhatia R, Bhardwaj I, Mishra V, Sharma K, Parkash C, et al. Molecular-agronomic characterization and genetic study reveals usefulness of refined Ogura cytoplasm based CMS lines in hybrid breeding of cauliflower (Brassica oleracea botrytis L.). Sci Hortic. 2017b; 224: 27-36.

44. Saha G, Park J-I, Kim H, Kang K-K, Cho Y-G, Nou I-S. MADS-Box genes are associated with the petaloidy/sepaloidy of the stamens in cytoplasmic male sterile Plant Breed Biotech.2016; 4: 40-50.

45. Meur G, Gaikwad K, Bhat SR, Prakash S, Kirti PB. Homeotic-like modification of stamens to petals is associated with aberrant mitochondrial gene expression in cytoplasmic male sterile Ogura Brassica juncea. J Genet. 2006; 85: 133-139.

46. Zhang Y, Wang X, Zhang W, Yu F, Tian J, Li D, Guo A. Functional analysis of the two Brassica AP3 genes involved in apetalous and stamen carpelloid phenotypes. PLOS ONE. 2011; 6: e20930.

https://doi.org/10.1371/journal.pone.0020930.

Page 16/39 
47. Zhang Y, Huang S, Wang X, Liu J, Guo X, Mu J, Tian J, Wang X. Defective APETALA2 genes lead to sepal modification in Brassica crops. Front Plant Sci. 2018; 9: 367.https://doi.org/10.3389/fpls.2018.00367.

48. Liu J, Li C-Q, Dong Y, Yang X, Wang Y-Z. Dosage imbalance of B- and C-class genes causes petaloid-stamen relating to $F_{1}$ hybrid variation. BMC Genomics. 2018; 18: 341. doi: 10.1186/s12870-018-1562-4.

49. Dey SS, Bhatia R, Parkash C, Sharma S, Dabral M, Mishra V, Bhardwaj I, Sharma K, Sharma VK, Kumar R. Alteration in important quality traits and antioxidant activities in Brassica oleraceawith Ogura cybrid cytoplasm. Plant Breed. 2017a; 136: 400-409.

50. Honma Y, Yoshida Y, Terachi T, Toriyama K, Mikami T, Kubo T. Polymorphic minisatellites in the mictochondrial DNAs of Oryza and Curr Genet. 2011; 57: 261-270.doi: 10.1007/s00294-011-0 345-3.

51. Warwick SI, Black LD. Molecular systematic of Brassica and allied genera (Subtribe Brassicinae, Brassiceae)chloroplast genome and cytodeme congruence. Theor Appl Genet. 1991; 82: 81-92.

52. Heng S, Chen F, Wei C, Hu K, Yang Z, Wen J, Yi B, Ma C, et al. Identification of different cytoplasms based on newly developed mitotype-specific markers for marker-assisted selection breeding in Brassica napus Plant Cell Rep. 2017;36: 901-909. doi: 10.1007/s00299-017-2121-4.

53. Chen L, Liu L, Jin P, Gong Y, Sun X, Ma E. Cytological and molecular identification of cytoplasm in two male sterile lines in radish. Mol Plant Breed. 2009; 7: 757-762.

54. Han F, Zhang X, Yang L, Zhuang M, Zhang Y, Li Z, Fang Z, Lv H. iTRAQ-based proteomic analysis of Ogura-CMS cabbage and its maintainer line. Int J Mol Sci. 2018;19: 3180. doi: 3390/ijms19103180.

55. Lin S, Miao Y, Su S, Xu J, Jin L, Sun Da, Peng R, Huang L, Cao J. Comprehensive analysis of Ogura cytoplasmic male sterility-related genes in turnip (Brassica raparapifera) using RNA sequencing analysis and bioinformatics. PLOS ONE. 2019; 14: e0218029. doi:10.1371/journal.pone.0218029.

56. Sheng X-G, Zhao Z-Q, Wang J-S, Yu H-F, Shen Y-S, Zeng X-Y, Gu H-H. Genome wide analysis of MADS-box gene family in Brassica oleracea reveals conservation and variation in flower development. BMC Plant Biol. 2019; 19: 106. doi: 10.1186/s12870-019-1717-y.

57. Shu J, Liu Y, Zhang L, Li Z, Fang Z, Yang L, Zhuang M, Zhang Y, Lv H. Evaluation and selection of sources of cytoplasmic male sterility in broccoli. Euphytica. 2019; 215: 125. doi: 10.1007/s10681-019-2453-y.

58. Dey SS, Sharma SR, Bhatia R, Kumar PR, Parkash C. Development and characterization of "Ogura" based improved CMS lines of cauliflower. Indian J Genet. 2011b; 71: 37-42.

59. Yang K, Nath UK, Biswas MK, Kayum MA, Yi G-e, Lee J, et al. Whole-genome sequencing of Brassica oleracea capitata reveals new diversity of the mitogenome. PLoS ONE. 2018; 13: e0194356. doi:

10.1371/journal.pone.0194356.

60. McCauley DE. Paternal leakage, heteroplasmy, and the evolution of plant mitochondrial genomes. New Phytol. 2013;200: 966-977. doi: 10.1111/nph.12431.

61. Birky CW Jr. Uniparental inheritance of mitochondrial and chloroplast genes: mechanisms and evolution. Proc Natl Acad Sci USA. 1995; 92: 11331-11338.

62. Reboud X, Zeyl C. Organelle inheritance in plants. Heredity. 1994; 72: 132-140.

63. Zhang YY, Fang ZY, Wang QB, Liu YM, Yang LM, Zhuang M, et al. Chloroplast subspecies-specific SNP detection and its maternal inheritance in Brassica oleracea by using a dCAPS marker. J Hered. 2012; 103: 606611..doi: 10.1093/jhered/ess006.

64. Erickson L, Kemble R. Paternal inheritance of mitochondria in rapeseed (Brassica napus). Mol Gen Genet. 1990; 222: 135-139. 
65. Testolin R, Cipriani G. Paternal inheritance of chloroplast DNA and maternal inheritance of mitochondrial DNA in the genus Actinidia. Theor Appl Genet.1997; 94: 897-903.

66. Worth JRP, Yokogawa M, Isagi Y. Outcrossing rates and organelle inheritance estimated from two natural populations of the Japanese endemic conifer Sciadopitysverticillata. J Plant Res. 2014; 127: 617-626. doi: 10.1007/s10265-014-0646-y.

67. Weihe A, Apitz J, Pohlheim F, Salinas-Hartwig A, Borner T. Biparental inheritance of plastidial and mitochondrial DNA and hybrid variegation in Mol Genet Genomics. 2009; 282: 587-593.

68. Hansen AK, Escobar LK, Gilbert LE, Jansen RK. Paternal, maternal, and biparental inheritance of the chloroplast genome in Passiflora (Passifloraceae): implications for phylogenetic studies. Am J Bot. 2007; 94: 42-46. doi: 10.3732/ajb.94.1.42.

69. Fenstter CB, Cheely G, Dudash MR, Reynolds RJ. Nectar reward and advertisement in hummingbird-pollinated Silene virginica (Caryophyllaceae). Am J Bot. 2006; 93: 1800-1807. doi: 10.3732/ajb.93.12.1800.

70. Parachnowitsch AL, Manson JS, Sletvold N. Evolutionary ecology of nectar. Ann Bot. 2019; 123: 247-261. doi: 11093/aob/mcy132.

71. Gomez JM, Bosch J, Perfectti F, Fernandez JD, Abdelaziz M, Camacho JPM. Association between floral traits and rewards in Erysimummediohispanicum(Brassicaceae). Ann Bot. 2008; 101: 1413-1420. doi:10.1093/aob/mcn053.

72. Dobler R, Rogell B, Budar F, Dowling DK. A meta-analysis of the strength and nature of cytoplasmic genetic effects. J Evol Biol. 2014; 27: 2021-2034. doi: 1111/jeb.12468.

73. Roux F, Mary-Huard T, Barillot E, Wenes E, Botran L, Durand S, Villoutreix R, Martin-Magniette ML, Camilleri C, Budar F. Cytonuclear interactions affect adaptive traits of the annual plant Arabidopsis thaliana in the field. Proc Natl Acad Sci USA. 2016; 113: 3687-3692. doi: 1073/pnas.1520687113.

74. Singh KH, Srivastava KK. Characterization of different cytoplasmic male sterility systems in Indian mustard (Brassica juncea Czern\&Coss). Plant Breed. 2006;125: 72-76.

75. Dey SS, Bhatia R, Pramanik A, Sharma K, Parkash C. A unique strategy to improve the floral traits and seed yield of Brassica oleracea cytoplasmic male sterile lines through honey bee-mediated selection. Euphytica. 2019; 215: 111. doi: 10.1007/s10681-019-2431-4.

76. Murray MG, Thompson WF. Rapid isolation of high molecular weight plant DNA. Nucleic Acid Res. 1980;8: 4321-4325. doi:10.1093/nar/8.19.4321.

77. Perrier X, Jacquemoud-Collet JP. DARwin software. http://darwin.cirad.fr/. 2006.

78. Altschul SF, Gish W, Miller W, Myers EW, Lipman DJ. Basic local alignment search tool. J Mol Biol. 1990;215: 403-410. doi: 10.1016/S0022-2836(05)80360-2.

79. Kumar S, Stecher G, Li M, Knyaz C, Tamura K. MEGA X: Molecular evolutionary genetics analysis across computing platforms. Mol Biol Evol. 2018;35: 1547-1549.

80. Sievers F, Wilm A, Dineen D, Gibson TJ, Karplus K, Li W, Lopez R, McWilliam H, Remmert M, Soding J, Thompson JD, Higgins DG. Fast, scalable generation of high-quality protein multiple sequence alignments using CLUSTAL Omega. Mol Sys Biol. 2011; 7: 539. https://doi.org/10.1038/msb.2011.75.

81. Gautam PK, Rathore RKS, Sutar AR, Mangle BB. Characterization of different male sterile lines on morphological characters of India mustard [Brassica juncea(L.) Czern\&Coss] along with their maintainer. Int Multidiscip Res J.2011;1: 04-08. 
82. Chang S, Yang T, Du T, Huang Y, Chen J, Yan J, He J, Guan R. Mitochondrial genome sequencing helps show the evolutionary mechanism of mitochondrial genome formation in Brassica. BMC Genomics. 2011; 12: 497. doi: 10.1186/1471-2164-12-497.

\section{Abbreviations}

PCR: Polymerase chain reaction

CMS: Cytoplasm male sterile

DNA: deoxyribonucleic acid

$R f$ : Restorer of fertility

SSI: Sporophytic self-incompatibility

ORF: Open reading frame

SSR: Simple sequence repeats

NCBI: National centre for biotechnology information

Mt-DMA: Mitochondrial DNA

PCA: Principal component analysis

NJ: Neighbour joining

SNP: Single nucleotide polymorphism

\section{Tables}

Table 1 Cauliflower cytoplasmic male sterile lines used in the present investigation 


\begin{tabular}{|c|c|c|c|c|c|}
\hline Sr. No & CMS accessions & Status & Developmental Stage & Source & Leafiness/Riceyness \\
\hline $\mathrm{A} 1$ & Ogu122-5A & CMS line & $\mathrm{BC}_{12}$ & IARI Katrain & Absent \\
\hline $\mathrm{A} 2$ & Ogu115-33A & CMS line & $\mathrm{BC}_{9}$ & IARI Katrain & Absent \\
\hline A3 & Ogu118-6A & CMS line & $\mathrm{BC}_{12}$ & IARI Katrain & Absent \\
\hline A4 & Ogu307-33A & CMS line & $\mathrm{BC}_{9}$ & IARI Katrain & Absent \\
\hline A5 & Ogu33-1A & CMS line & $\mathrm{BC}_{9}$ & IARI Katrain & Absent \\
\hline A6 & Ogu1A & CMS line & $\mathrm{BC}_{9}$ & IARI Katrain & Absent \\
\hline A7 & Ogu309-2A & CMS line & $\mathrm{BC}_{13}$ & IARI Katrain & Absent \\
\hline A8 & OguKt-2-6A & CMS line & $\mathrm{BC}_{12}$ & IARI Katrain & Absent \\
\hline A9 & Ogu13-85-6A & CMS line & $\mathrm{BC}_{12}$ & IARI Katrain & Absent \\
\hline A10 & Ogu16A & CMS line & $\mathrm{BC}_{9}$ & IARI Katrain & Absent \\
\hline A11 & Ogu3A & CMS line & $\mathrm{BC}_{9}$ & IARI Katrain & Absent \\
\hline A12 & Ogu2-6A & CMS line & $\mathrm{BC}_{11}$ & IARI Katrain & Absent \\
\hline A13 & Ogu2A & CMS line & $\mathrm{BC}_{9}$ & IARI Katrain & Absent \\
\hline A14 & Ogu14A & CMS line & $\mathrm{BC}_{9}$ & IARI Katrain & Absent \\
\hline A15 & Ogu122-1A & CMS line & $\mathrm{BC}_{13}$ & IARI Katrain & Absent \\
\hline A16 & OguKt-9-2A & CMS line & $\mathrm{BC}_{13}$ & IARI Katrain & Absent \\
\hline A17 & Ogu121-1A & CMS line & $\mathrm{BC}_{12}$ & IARI Katrain & Absent \\
\hline A18 & Ogu126-1A & CMS line & $\mathrm{BC}_{13}$ & IARI Katrain & Absent \\
\hline A19 & Ogu134-8A & CMS line & $\mathrm{BC}_{12}$ & IARI Katrain & Absent \\
\hline A20 & Ogu12A & CMS line & $\mathrm{BC}_{9}$ & IARI Katrain & Absent \\
\hline A21 & Ogu119-1A & CMS line & $\mathrm{BC}_{13}$ & IARI Katrain & Absent \\
\hline $\mathrm{A} 22$ & Ogu34A & CMS line & $\mathrm{BC}_{9}$ & IARI Katrain & Absent \\
\hline A23 & Ogu178-8A & CMS line & $\mathrm{BC}_{12}$ & IARI Katrain & Absent \\
\hline A24 & Ogu118-2A & CMS line & $\mathrm{BC}_{11}$ & IARI Katrain & Absent \\
\hline A25 & Ogu33A & CMS line & $\mathrm{BC}_{9}$ & IARI Katrain & Absent \\
\hline A26 & HVCF-29 & Hybrid & - & AcsenHyVeg & Absent \\
\hline A27 & HVCF-18 & Hybrid & - & AcsenHyVeg & Absent \\
\hline
\end{tabular}




\begin{tabular}{llllll} 
A28 & HVCF-16 & Hybrid & - & AcsenHyVeg & Absent \\
\hline A29 & OguKt-2-1A & CMS line & $\mathrm{BC}_{12}$ & IARI Katrain & Absent \\
\hline A30 & Ogu309-1A & CMS line & $\mathrm{BC}_{11}$ & IARI Katrain & Absent \\
\hline A31 & Ogu-HL-1A & CMS line & $\mathrm{BC}_{11}$ & IARI Katrain & Absent \\
\hline A32 & Ogu307-1A & CMS line & $\mathrm{BC}_{12}$ & IARI Katrain & Absent \\
\hline A33 & Ogu Kt-8-2A & CMS line & $\mathrm{BC}_{12}$ & IARI Katrain & Absent \\
\hline A34 & Ogu119-2A & CMS line & $\mathrm{BC}_{11}$ & IARI Katrain & Absent \\
\hline A35 & Ogu121-2A & CMS line & $\mathrm{BC}_{11}$ & IARI Katrain & Absent \\
\hline A36 & Ogu-HL-3A & CMS line & $\mathrm{BC}_{11}$ & IARI Katrain & Absent
\end{tabular}

Table 1 ContinueCauliflower cytoplasmic male sterile lines used in the present investigation 


\begin{tabular}{|c|c|c|c|c|c|}
\hline Sr. No & CMS line & Status & Developmental Stage & Origin of CMS sources & Leafiness/Riceyness \\
\hline A37 & Ogu13-85-3A & CMS line & $\mathrm{BC}_{11}$ & IARI Katrain & Absent \\
\hline A38 & Ogu119-6A & CMS line & $\mathrm{BC}_{12}$ & IARI Katrain & Absent \\
\hline A39 & Snowpearl & Hybrid & - & Syngenta & Absent \\
\hline A40 & CFH-1522 & Hybrid & - & Syngenta & Absent \\
\hline A41 & Kimaya & Hybrid & - & Syngenta & Absent \\
\hline A42 & Pahuja & Hybrid & - & Pahuja seeds & Absent \\
\hline A43 & Ogu13A & CMS line & $\mathrm{BC}_{9}$ & IARI Katrain & Absent \\
\hline A44 & Ogu34-1A & CMS line & $\mathrm{BC}_{9}$ & IARI Katrain & Absent \\
\hline A45 & Ogu1-2A & CMS line & $\mathrm{BC}_{12}$ & IARI Katrain & Absent \\
\hline A46 & Ogu13-85-2A & CMS line & $\mathrm{BC}_{11}$ & IARI Katrain & Absent \\
\hline A47 & Ogu118-3A & CMS line & $\mathrm{BC}_{12}$ & IARI Katrain & Absent \\
\hline A48 & Ogu307-6A & CMS line & $\mathrm{BC}_{12}$ & IARI Katrain & Absent \\
\hline A49 & Ogu-HL-6A & CMS line & $\mathrm{BC}_{11}$ & IARI Katrain & Absent \\
\hline A50 & Ogu308-6A & CMS line & $\mathrm{BC}_{12}$ & IARI Katrain & Absent \\
\hline A51 & Ogu13-01-5A & CMS line & $\mathrm{BC}_{9}$ & IARI Katrain & Absent \\
\hline A52 & Ogu13-85-4A & CMS line & $\mathrm{BC}_{11}$ & IARI Katrain & Absent \\
\hline A53 & Ogu118-4A & CMS line & $\mathrm{BC}_{12}$ & IARI Katrain & Absent \\
\hline A54 & Ogu76-4A & CMS line & $\mathrm{BC}_{9}$ & IARI Katrain & Absent \\
\hline A55 & Ogu33-4A & CMS line & $\mathrm{BC}_{9}$ & IARI Katrain & Absent \\
\hline A56 & Ogu77-4A & CMS line & $\mathrm{BC}_{12}$ & IARI Katrain & Absent \\
\hline A57 & Ogu13-85-33A & CMS line & $\mathrm{BC}_{11}$ & IARI Katrain & Absent \\
\hline A58 & Ogu76-33A & CMS line & $\mathrm{BC}_{11}$ & IARI Katrain & Absent \\
\hline A59 & Ogu122-8A & CMS line & $\mathrm{BC}_{12}$ & IARI Katrain & Absent \\
\hline A60 & Ogu1-8A & CMS line & $\mathrm{BC}_{12}$ & IARI Katrain & Absent \\
\hline A61 & Ogu309-8A & CMS line & $\mathrm{BC}_{13}$ & IARI Katrain & Absent \\
\hline A62 & Ogu115-8A & CMS line & $\mathrm{BC}_{13}$ & IARI Katrain & Absent \\
\hline A63 & Ogu310-8A & CMS line & $\mathrm{BC}_{11}$ & IARI Katrain & Absent \\
\hline A64 & Ogu34-1-8A & CMS line & & IARI Katrain & Absent \\
\hline
\end{tabular}


$\mathrm{BC}_{12}$

\begin{tabular}{llllll}
\hline A65 & Ogu34-8A & CMS line & BC $_{12}$ & IARI Katrain & Absent \\
\hline A66 & Ogu-HL-50A & CMS line & BC $_{11}$ & IARI Katrain & Absent \\
\hline A67 & Brahma & Hybrid & - & Sakata & Absent \\
\hline A68 & Ogu15A & CMS line & BC $_{9}$ & IARI Katrain & Absent \\
\hline A69 & Ogu17A & CMS line & BC $_{9}$ & IARI Katrain & Absent \\
\hline A70 & Ogu50A & CMS line & BC $_{9}$ & IARI Katrain & Absent \\
\hline A71 & Ogu60A & CMS line & $\mathrm{BC}_{10}$ & IARI Katrain & Absent \\
\hline A72 & Casper & Hybrid & - & RijkZwaan & Absent \\
\hline A73 & KTCF-10A & Hybrid & - & Private seed & Absent \\
\hline A74 & Ponder & Hybrid & - & RijkZwaan & Absent \\
\hline A75 & SM & Hybrid & - & RijkZwaan & Absent \\
\hline A76 & Indam & Hybrid & - & IAHS & Absent
\end{tabular}

Table 2 Sequence similarity percentage of the selected polymorphic amplicons of cauliflower CMS accessions generated by mt-SSR (BnTR4) with corresponding mitogenome sequences 


\begin{tabular}{|c|c|c|c|c|c|c|}
\hline $\begin{array}{l}\text { Accession } \\
\text { no }\end{array}$ & Species & Description & $\begin{array}{l}\text { Sequence } \\
\text { identity } \\
\text { (Ogu307- } \\
\text { 33A) }\end{array}$ & $\begin{array}{l}\text { Sequence } \\
\text { identity } \\
\text { (Ogu33- } \\
\text { 1A) }\end{array}$ & $\begin{array}{l}\text { Sequence } \\
\text { identity } \\
\text { (Ogu16A) }\end{array}$ & $\begin{array}{l}\text { Sequence } \\
\text { identity } \\
\text { (Ogu12A) }\end{array}$ \\
\hline KU831325.1 & $\begin{array}{l}\text { Brassica } \\
\text { oleracea } \\
\text { var. } \\
\text { capitata }\end{array}$ & $\begin{array}{l}\text { mitochondrion, } \\
\text { complete genome }\end{array}$ & $97.12 \%$ & $97.12 \%$ & $96.60 \%$ & $95.24 \%$ \\
\hline KJ820683.1 & $\begin{array}{l}\text { Brassica } \\
\text { oleracea } \\
\text { var. } \\
\text { botrytis }\end{array}$ & $\begin{array}{l}\text { mitochondrion, } \\
\text { complete genome }\end{array}$ & $97.12 \%$ & $97.12 \%$ & $96.60 \%$ & $95.24 \%$ \\
\hline AB627043.1 & $\begin{array}{l}\text { Brassica } \\
\text { oleracea }\end{array}$ & $\begin{array}{l}\text { mitochondrial DNA, } \\
\text { minisatellite: BnTR4 }\end{array}$ & $99.47 \%$ & $98.95 \%$ & $99.12 \%$ & $99.10 \%$ \\
\hline AP012988.1 & $\begin{array}{l}\text { Brassica } \\
\text { oleracea }\end{array}$ & $\begin{array}{l}\text { mitochondrial DNA, } \\
\text { complete sequence, } \\
\text { cultivar: Fujiwase }\end{array}$ & $97.12 \%$ & $97.12 \%$ & $96.60 \%$ & $95.24 \%$ \\
\hline JF920286.1 & $\begin{array}{l}\text { Brassica } \\
\text { oleracea }\end{array}$ & $\begin{array}{l}\text { mitochondrial DNA, } \\
\text { complete genome }\end{array}$ & $97.12 \%$ & $97.12 \%$ & $96.60 \%$ & $95.24 \%$ \\
\hline AP018472.1 & $\begin{array}{l}\text { Raphanus } \\
\text { sativus }\end{array}$ & $\begin{array}{l}\text { mitochondrial DNA, } \\
\text { complete genome, } \\
\text { cultivar: Kosena }\end{array}$ & $95.86 \%$ & $95.77 \%$ & $96.79 \%$ & $95.87 \%$ \\
\hline AP012989.1 & $\begin{array}{l}\text { Brassica } \\
\text { nigra }\end{array}$ & $\begin{array}{l}\text { mitochondrial DNA, } \\
\text { complete sequence }\end{array}$ & $96.55 \%$ & $95.86 \%$ & $96.33 \%$ & $95.41 \%$ \\
\hline
\end{tabular}

Table 3 Sequence similarity percentage of the selected polymorphic amplicons of cauliflower CMS accessions generated by mt-SSR (orf125) with corresponding mitogenome sequences 


\begin{tabular}{|c|c|c|c|c|c|c|}
\hline $\begin{array}{l}\text { Accession } \\
\text { no }\end{array}$ & Species & Description & $\begin{array}{l}\text { Sequence } \\
\text { identity } \\
\text { (Ogu50A) }\end{array}$ & $\begin{array}{l}\text { Sequence } \\
\text { identity } \\
\text { (Ogu12A) }\end{array}$ & $\begin{array}{l}\text { Sequence } \\
\text { identity } \\
\text { (Ogu121- } \\
\text { 2A) }\end{array}$ & $\begin{array}{l}\text { Sequence } \\
\text { identity } \\
\text { (Ogu17A) }\end{array}$ \\
\hline KU831325.1 & $\begin{array}{l}\text { Brassica } \\
\text { oleraceavar. } \\
\text { capitata }\end{array}$ & $\begin{array}{l}\text { mitochondrion, } \\
\text { complete genome }\end{array}$ & $99.34 \%$ & $99.06 \%$ & $99.06 \%$ & $99.36 \%$ \\
\hline KJ820683.1 & $\begin{array}{l}\text { Brassica } \\
\text { oleracea } \\
\text { var. botrytis }\end{array}$ & $\begin{array}{l}\text { mitochondrion, } \\
\text { complete genome }\end{array}$ & $99.34 \%$ & $99.06 \%$ & $99.06 \%$ & $99.36 \%$ \\
\hline AB694744.1 & $\begin{array}{l}\text { Raphanus } \\
\text { sativus }\end{array}$ & $\begin{array}{l}\text { mitochondrial DNA, } \\
\text { complete genome, } \\
\text { cultivar: MS-gensuke }\end{array}$ & $99.08 \%$ & $98.82 \%$ & $98.58 \%$ & $96.88 \%$ \\
\hline AP012990.1 & $\begin{array}{l}\text { Raphanus } \\
\text { sativus }\end{array}$ & $\begin{array}{l}\text { mitochondrial DNA, } \\
\text { complete sequence, } \\
\text { cultivar: Black radish }\end{array}$ & $99.39 \%$ & $98.58 \%$ & $98.35 \%$ & $96.63 \%$ \\
\hline JF920287.1 & $\begin{array}{l}\text { Brassica } \\
\text { carinata }\end{array}$ & $\begin{array}{l}\text { mitochondrial DNA, } \\
\text { complete genome }\end{array}$ & $99.39 \%$ & $98.58 \%$ & $98.35 \%$ & $96.63 \%$ \\
\hline AP018472.1 & $\begin{array}{l}\text { Raphanus } \\
\text { sativus }\end{array}$ & $\begin{array}{l}\text { mitochondrial DNA, } \\
\text { complete genome, } \\
\text { cultivar: Kosena }\end{array}$ & $99.08 \%$ & $98.82 \%$ & $98.58 \%$ & $96.88 \%$ \\
\hline AP012989.1 & $\begin{array}{l}\text { Brassica } \\
\text { nigra }\end{array}$ & $\begin{array}{l}\text { mitochondrial DNA, } \\
\text { complete sequence }\end{array}$ & $99.39 \%$ & $98.58 \%$ & $98.35 \%$ & $96.63 \%$ \\
\hline MG872827.1 & $\begin{array}{l}\text { Brassica } \\
\text { juncea }\end{array}$ & $\begin{array}{l}\text { isolate } 93 \\
\text { mitochondrion, } \\
\text { complete genome }\end{array}$ & $99.39 \%$ & $98.58 \%$ & $98.35 \%$ & $96.63 \%$ \\
\hline
\end{tabular}

Table 4Impact of cytoplasmic genetic variations based on InDels on floral phenotypesin varying nuclear backgrounds 


\begin{tabular}{|c|c|c|c|c|c|}
\hline \multirow[t]{2}{*}{ Code } & \multirow[t]{2}{*}{$\begin{array}{l}\text { CMS } \\
\text { accessions }\end{array}$} & \multicolumn{2}{|c|}{$\begin{array}{l}\text { Type of nucleotide variation } \\
\text { (SNPs/Deletions) }\end{array}$} & \multicolumn{2}{|c|}{$\begin{array}{l}\text { Flower Phenotype of cytolines } \\
\text { (CMS) }\end{array}$} \\
\hline & & (BnTR4) & (Orf125) & Normal & Varying Abnormalities \\
\hline A1 & Ogu122-5A & - & - & NCMS & \\
\hline A2 & Ogu115-33A & - & $1(51)$ & & A \\
\hline A3 & Ogu118-6A & - & - & NCMS & \\
\hline A4 & Ogu307-33A & $1(\mathrm{~T} / \mathrm{C})$ & $1(51)$ & & $A, B F, G$ \\
\hline A5 & Ogu33-1A & $1(\mathrm{~T} / \mathrm{C})$ & $1(51)$ & & $A, B, G$ \\
\hline A7 & Ogu309-2A & $1(31)$ & $1(51)$ & & $A, F, G$ \\
\hline A8 & OguKt-2-6A & - & - & NCMS & \\
\hline A9 & Ogu13-85-6A & - & - & NCMS & \\
\hline A10 & Ogu16A & $1(\mathrm{C} / \mathrm{T}), 1(31)$ & $1(51)$ & & $B, F, J$ \\
\hline A11 & Ogu3A & $1(31)$ & $1(51)$ & & $B, J$ \\
\hline A12 & Ogu2-6A & - & - & NCMS & \\
\hline A13 & Ogu2A & $1(31)$ & $1(51)$ & & $F, I, J$ \\
\hline A14 & Ogu14A & $1(31)$ & $1(51)$ & & $\mathrm{J}$ \\
\hline A15 & Ogu122-1A & $1(31)$ & $1(51)$ & & $J$ \\
\hline A16 & OguKt-9-2A & $1(31)$ & $1(51)$ & & $\mathrm{J}, \mathrm{K}$ \\
\hline A17 & Ogu121-1A & $1(31)$ & $1(51)$ & & $\mathrm{J}$ \\
\hline A18 & Ogu126-1A & $1(31)$ & $1(51)$ & & $\mathrm{J}$ \\
\hline A19 & Ogu134-8A & - & - & NCMS & \\
\hline A20 & Ogu12A & $1(\mathrm{C} / \mathrm{T}), 1(31)$ & $1(51)$ & & $F, I, J$ \\
\hline A21 & Ogu119-1A & - & $1(51)$ & & A \\
\hline A22 & Ogu34A & - & $1(51)$ & & A \\
\hline A23 & Ogu178-8A & - & - & NCMS & \\
\hline A24 & Ogu118-2A & $1(31)$ & $1(51)$ & & $G, J$ \\
\hline A25 & Ogu33A & - & $1(51)$ & & A \\
\hline A29 & OguKt-2-1 A & $1(31)$ & $1(51)$ & & $\mathrm{J}, \mathrm{K}$ \\
\hline A30 & Ogu309-1A & $1(31)$ & $1(51)$ & & $\mathrm{I}, \mathrm{J}$ \\
\hline A31 & Ogu-HL-1A & $1(31)$ & $1(51)$ & & $\mathrm{L}$ \\
\hline A32 & Ogu307-1A & $1(31)$ & $1(51)$ & & A \\
\hline A33 & Ogu Kt-8-2A & $1(31)$ & $1(51)$ & & $\mathrm{J}, \mathrm{K}$ \\
\hline A34 & Ogu119-2A & $1(31)$ & $\begin{array}{l}1(51) \\
26 / 39\end{array}$ & & A \\
\hline
\end{tabular}




$\begin{array}{lllcr}\text { A35 } & \text { Ogu121-2A } & 1(31) & 1(51) & \text { I, J, K } \\ \text { A36 } & \text { Ogu-HL-3A } & 1(31) & 1(51) & \text { A, C }\end{array}$

(A) Adherence of functional stamens with style; (B) Homeotic-like floral transformation: petaloidy condition of stamens; (C) partial petaloidy of functional stamens; (D) splitted style along with adherence of stamens; (E) stigma hidden inside the petals; $(F)$ splitted style along with exposed ovules; $(G)$ unopened flower; $(H)$ stamens adherence with style and crooked stigma; (I) partially opened flowers; (J) Absence of non-functional stamens; (K) Fused flower; (L) Very curved functional stamens with crooked stigma; (M) absence of nectaries; (NCMS) Cytoplasmic male sterile sources with normal flower phenotype and devoid of other abnormalities as mentioned in A-M. Although, the conventional changes in flower morphology owing to cyto-nuclear interaction are evident; (+) sign denotes presence; (51)The number in parenthesis under the column deletions denote the number of base pair deletions

Table 4lmpact of cytoplasmic genetic variations based on InDels on floral phenotypes in varying nuclear backgrounds 


\begin{tabular}{|c|c|c|c|c|c|}
\hline \multirow[t]{2}{*}{$\begin{array}{l}\text { Sr. } \\
\text { No }\end{array}$} & \multirow[t]{2}{*}{ CMS line } & \multicolumn{2}{|c|}{$\begin{array}{l}\text { Type of nucleotide variation } \\
\text { (SNPs/Deletions) }\end{array}$} & \multicolumn{2}{|c|}{$\begin{array}{l}\text { Flower Phenotype of cytolines } \\
\text { (CMS) }\end{array}$} \\
\hline & & (BnTR4) & (Orf125) & Normal & Varying Abnormalities \\
\hline A37 & Ogu13-85-3A & $1(31)$ & $1(51)$ & & $B, I$ \\
\hline A38 & Ogu119-6A & - & - & NCMS & \\
\hline A43 & Ogu13A & - & - & NCMS & \\
\hline A44 & Ogu34-1A & - & $1(51)$ & & A \\
\hline A45 & Ogu1-2A & $1(31)$ & $1(51)$ & & I \\
\hline A46 & Ogu13-85-2A & $1(31)$ & $1(51)$ & & B, J \\
\hline A47 & Ogu118-3A & $1(31)$ & $1(51)$ & & $B, J$ \\
\hline A48 & Ogu307-6A & - & - & NCMS & \\
\hline A49 & Ogu-HL-6A & - & - & NCMS & \\
\hline A50 & Ogu308-6A & - & - & NCMS & \\
\hline A51 & Ogu13-01-5A & - & - & NCMS & L \\
\hline A52 & Ogu13-85-4A & 1 (31) & $1(51)$ & & M \\
\hline A53 & Ogu118-4A & $1(31)$ & $1(51)$ & & $B, K$ \\
\hline A54 & Ogu76-4A & $1(31)$ & $1(51)$ & & $A, K$ \\
\hline A55 & Ogu33-4A & $1(31)$ & $1(51)$ & & $A, K$ \\
\hline A56 & Ogu77-4A & $1(31)$ & $1(51)$ & & $B, C, E$ \\
\hline A57 & $\begin{array}{l}\text { Ogu13-85- } \\
33 \mathrm{~A}\end{array}$ & - & $1(51)$ & & A \\
\hline A58 & Ogu76-33A & - & $1(51)$ & & A \\
\hline A59 & Ogu122-8A & - & - & NCMS & \\
\hline A60 & Ogu1-8A & - & - & NCMS & \\
\hline A61 & Ogu309-8A & - & - & NCMS & \\
\hline A62 & Ogu115-8A & - & - & NCMS & \\
\hline A63 & Ogu310-8A & - & - & NCMS & \\
\hline A64 & Ogu34-1-8A & - & - & NCMS & \\
\hline A65 & Ogu34-8A & - & - & NCMS & \\
\hline A66 & Ogu-HL-50A & - & - & NCMS & \\
\hline A68 & Ogu15A & - & - & NCMS & \\
\hline A69 & Ogu17A & $1(31)$ & $1(51)$ & & L \\
\hline A70 & Ogu50A & - & - & NCMS & \\
\hline
\end{tabular}


- Adherence of functional stamens with style; (B) Homeotic-like floral transformation: petaloidy condition of stamens; (C) partial petaloidy of functional stamens; (D) splitted style along with adherence of stamens; (E) stigma hidden inside the petals; (F) splitted style along with exposed ovules; $(G)$ unopened flower; $(H)$ stamens adherence with style and crooked stigma; (I) partially opened flowers; (J) Absence of non-functional stamens; (K) Fused flower; (L) Very curved functional stamens with crooked stigma; (M) absence of nectaries; (NCMS) Cytoplasmic male sterile sources with normal flower phenotype and devoid of other abnormalities as mentioned in A-M. Although, the conventional changes in flower morphology owing to cyto-nuclear interaction are evident; (+) sign denotes presence; (51)The number in parenthesis under the column deletions denote the number 0

- $\mathrm{f}$ base pair deletions

Table 5Impact of cytonuclear interactions on nectar production of cytolines in varying nuclear backgrounds 


\begin{tabular}{|c|c|c|c|c|c|c|c|c|}
\hline $\begin{array}{l}A \text { and } B \\
\text { lines }\end{array}$ & $\begin{array}{l}\text { Nectar } \\
\text { Quantity } \\
(\mu \mathrm{l})\end{array}$ & $\begin{array}{l}\% \text { Nectar } \\
\text { Reduction } \\
\text { in } \\
\text { cytolines }\end{array}$ & $\begin{array}{l}A \text { and } B \\
\text { lines }\end{array}$ & $\begin{array}{l}\text { Nectar } \\
\text { Quantity } \\
(\mu l)\end{array}$ & $\begin{array}{l}\% \text { Nectar } \\
\text { Reduction } \\
\text { in } \\
\text { cytolines }\end{array}$ & $\begin{array}{l}A \text { and } B \\
\text { lines }\end{array}$ & $\begin{array}{l}\text { Nectar } \\
\text { Quantity } \\
(\mu l)\end{array}$ & $\begin{array}{l}\% \text { Nectar } \\
\text { Reduction } \\
\text { in } \\
\text { cytolines }\end{array}$ \\
\hline $\begin{array}{l}\text { Ogu33- } \\
1 \mathrm{~A}\end{array}$ & $0.44^{\star \star}$ & 73.17 & Ogu1A & $1.53^{\star \star}$ & 85.57 & $\begin{array}{l}\text { Ogu2- } \\
6 \mathrm{~A}\end{array}$ & $3.66^{\star *}$ & 65.50 \\
\hline Kt-33B1 & 1.64 & & $\mathrm{Kt}-1 \mathrm{~B}$ & 10.61 & & $\mathrm{Kt}-1 \mathrm{~B}$ & 10.61 & \\
\hline Ogu33A & 0.38 ** & 78.28 & Ogu12A & $2.24^{\star \star}$ & 83.93 & $\begin{array}{l}\text { Ogu115- } \\
33 \mathrm{~A}\end{array}$ & $2.02^{\star}$ & 30.34 \\
\hline Kt-33B & 1.75 & & $\mathrm{Kt}-12 \mathrm{~B}$ & 13.94 & & Kt-15B & 2.90 & \\
\hline $\begin{array}{l}\text { Ogu34- } \\
1 \mathrm{~A}\end{array}$ & 0.60 ** & 75.6 & Ogu16A & $0.44^{*}$ & 84.82 & $\begin{array}{l}\text { Ogu307- } \\
33 \mathrm{~A}\end{array}$ & $0.87 *$ & 73.47 \\
\hline $\begin{array}{l}\text { Kt-34B } \\
\text { (WF) }\end{array}$ & 2.46 & & $\mathrm{Kt}-16 \mathrm{~B}$ & 2.90 & & $\begin{array}{l}\text { Kt-307- } \\
33 \mathrm{~B}\end{array}$ & 3.28 & \\
\hline Ogu34A & $0.65^{\star}$ & 67.82 & $\begin{array}{l}\text { OguKt-2- } \\
1 \mathrm{~A}\end{array}$ & $0.49 *$ & 84.82 & $\begin{array}{l}\text { Ogu1- } \\
8 A\end{array}$ & $5.69 * *$ & 46.37 \\
\hline $\begin{array}{l}\text { Kt-34B } \\
(\mathrm{YF})\end{array}$ & 2.02 & & $\mathrm{Kt}-2 \mathrm{~B}$ & 3.23 & & $\mathrm{Kt}-1 \mathrm{~B}$ & 10.61 & \\
\hline Ogu15A & $0.28^{\star}$ & 86.13 & $\begin{array}{l}\text { Ogu121- } \\
\text { 1A }\end{array}$ & 1.42 & 15.97 & $\begin{array}{l}\text { Ogu13- } \\
\text { 85-3A }\end{array}$ & $0.55^{\star}$ & 49.54 \\
\hline Kt-15B & 2.02 & & $\mathrm{Kt}-121 \mathrm{~B}$ & 1.69 & & $\begin{array}{l}\text { Kt- } \\
1385 B\end{array}$ & 1.09 & \\
\hline Ogu17A & $0.66^{\star \star}$ & 76.76 & $\begin{array}{l}\text { Ogu121- } \\
2 \mathrm{~A}\end{array}$ & $0.33^{*}$ & 76.76 & Ogu2A & $2.24^{\star}$ & 30.65 \\
\hline Kt-17B & 2.84 & & $\mathrm{Kt}-121 \mathrm{~B}$ & 1.42 & & $\mathrm{Kt}-2 \mathrm{~B}$ & 3.23 & \\
\hline $\begin{array}{l}\text { Ogu119- } \\
\text { 1A }\end{array}$ & $1.37^{\star}$ & 32.17 & Ogu1-2A & $0.38 *$ & 88.23 & Ogu3A & $0.55^{\star}$ & 81.35 \\
\hline $\begin{array}{l}\text { RSK- } \\
119 B\end{array}$ & 2.02 & & $\mathrm{Kt}-2 \mathrm{~B}$ & 3.23 & & $\mathrm{Kt}-3 \mathrm{~B}$ & 2.95 & \\
\hline $\begin{array}{l}\text { Ogu307- } \\
1 \mathrm{~A}\end{array}$ & $1.48^{\star \star}$ & 54.87 & Ogu-77-6A & $0.55^{\star}$ & 56.34 & Ogu13A & $1.59 * *$ & 53.09 \\
\hline Kt-307B & 3.28 & & Kt-77 & 1.26 & & Kt-13B & 3.39 & \\
\hline $\begin{array}{l}\text { Ogu309- } \\
1 \mathrm{~A}\end{array}$ & $0.60^{\star \star}$ & 64.49 & Ogu-HL-6A & $0.40^{\star \star}$ & 90.74 & Ogu14A & $0.55^{\star \star}$ & 85.21 \\
\hline Kt-309B & 1.69 & & $\mathrm{HL}$ & 4.32 & & $\mathrm{Kt}-14 \mathrm{~B}$ & 3.72 & \\
\hline $\begin{array}{l}\text { Ogu-HL- } \\
1 \mathrm{~A}\end{array}$ & $0.49 * \star$ & 88.65 & $\begin{array}{l}\text { Ogu122- } \\
5 A\end{array}$ & $1.91^{\star *}$ & 74.66 & $\begin{array}{l}\text { Ogu119- } \\
2 A\end{array}$ & $0.55^{\star}$ & 72.77 \\
\hline $\mathrm{HL}$ & 4.32 & & $\mathrm{Kt}-22 \mathrm{~B}$ & 7.54 & & $\begin{array}{l}\text { RSK- } \\
119 B\end{array}$ & 2.02 & \\
\hline $\begin{array}{l}\text { Ogu309- } \\
2 \mathrm{~A}\end{array}$ & $0.93^{\star}$ & 44.97 & $\begin{array}{l}\text { Ogu122- } \\
8 \mathrm{~A}\end{array}$ & $0.98^{\star \star}$ & 87.00 & $\begin{array}{l}\text { Ogu13- } \\
85-2 A\end{array}$ & 0.55 & 49.54 \\
\hline \multirow[t]{2}{*}{ Kt-309B } & 1.69 & & $\mathrm{Kt}-22 \mathrm{~B}$ & 7.54 & & Kt- & 1.09 & \\
\hline & & & & Page 30/39 & & & & \\
\hline
\end{tabular}


1385B

\begin{tabular}{|c|c|c|c|c|c|c|c|c|}
\hline $\begin{array}{l}\text { Ogu1301- } \\
5 \AA\end{array}$ & $3.61^{*}$ & 24.15 & $\begin{array}{l}\text { Ogu309- } \\
8 A\end{array}$ & 2.35 & 10.30 & $\begin{array}{l}\text { Ogu118- } \\
2 A\end{array}$ & $0.71^{\star}$ & 73.99 \\
\hline Kt-1301B & 4.76 & & Kt-309-8B & 2.62 & & Kt-18B & 2.73 & \\
\hline $\begin{array}{l}\text { Ogu-HL- } \\
3 A\end{array}$ & $0.55^{\star \star}$ & 87.26 & $\begin{array}{l}\text { Ogu118- } \\
4 A\end{array}$ & $0.44^{*}$ & 83.88 & $\begin{array}{l}\text { Ogu119- } \\
6 \mathrm{~A}\end{array}$ & $0.38 *$ & 81.18 \\
\hline $\mathrm{HL}$ & 4.32 & & Kt-18B & 2.73 & & $\begin{array}{l}\text { RSK- } \\
119 B\end{array}$ & 2.02 & \\
\hline $\begin{array}{l}\text { Ogu76- } \\
4 \AA\end{array}$ & $1.09 *$ & 70.21 & Kn81.1301 & $0.54^{\star \star}$ & 88.65 & $\begin{array}{l}\text { Ogu13- } \\
85-6 A\end{array}$ & 0.98 & 10.09 \\
\hline DC-76 & 3.66 & & Kt-1301B & 4.76 & & $\begin{array}{l}\text { Kt- } \\
1385 B\end{array}$ & 1.09 & \\
\hline $\begin{array}{l}\text { Ogu } 76- \\
33 A\end{array}$ & $1.04^{\star}$ & 71.58 & $\begin{array}{l}\text { Ogu13-85- } \\
33 A\end{array}$ & $0.44^{*}$ & 59.63 & $\begin{array}{l}\text { Ogu118- } \\
6 \AA\end{array}$ & $0.87 *$ & 68.13 \\
\hline DC-76 & 3.66 & & Kt-1385B & 1.09 & & Kt-18B & 2.73 & \\
\hline $\begin{array}{l}\text { Ogu77- } \\
4 \AA\end{array}$ & $0.66^{*}$ & 47.61 & $\begin{array}{l}\text { Ogu122- } \\
1 \mathrm{~A}\end{array}$ & $0.49 * *$ & 93.50 & $\begin{array}{l}\text { OguKt- } \\
2-6 \mathrm{~A}\end{array}$ & $0.86^{\star}$ & 68.13 \\
\hline $\mathrm{Kt}-77 \mathrm{~B}$ & 1.26 & & $\mathrm{Kt}-22 \mathrm{~B}$ & 7.54 & & $\mathrm{Kt}-2 \mathrm{~B}$ & 2.73 & \\
\hline $\begin{array}{l}\text { Ogu310- } \\
8 \AA\end{array}$ & 0.60 & 26.82 & $\begin{array}{l}\text { Ogu126- } \\
1 A\end{array}$ & $2.95^{\star \star}$ & 78.76 & $\begin{array}{l}\text { Ogu-13- } \\
01-33 A\end{array}$ & $1.37 \star$ & 71.21 \\
\hline Kt-310B & 0.82 & & $\mathrm{Kt}-126 \mathrm{~B}$ & 13.89 & & $\begin{array}{l}\text { Kt- } \\
1301 B\end{array}$ & 4.76 & \\
\hline $\begin{array}{l}\text { Ogu178- } \\
8 \AA\end{array}$ & $1.86^{*}$ & 35.86 & $\begin{array}{l}\text { OguKt-9- } \\
2 A\end{array}$ & $1.04^{\star \star}$ & 83.75 & $\begin{array}{l}\text { Ogu115- } \\
8 A\end{array}$ & $1.05^{\star}$ & 48.01 \\
\hline Kt-178B & 2.90 & & $\mathrm{Kt}-9 \mathrm{~B}$ & 6.40 & & $\mathrm{Kt}-15 \mathrm{~B}$ & 2.02 & \\
\hline $\begin{array}{l}\text { Ogu-HL- } \\
50 \mathrm{~A}\end{array}$ & $0.66^{* *}$ & 84.72 & $\begin{array}{l}\text { OguKt-8- } \\
2 A\end{array}$ & $1.04^{\star \star}$ & 91.61 & & & \\
\hline $\mathrm{HL}$ & 4.32 & & $\mathrm{Kt}-8 \mathrm{~B}$ & 12.41 & & & & \\
\hline $\begin{array}{l}\text { Ogu13- } \\
85-4 A\end{array}$ & $0.66^{*}$ & 39.44 & $\begin{array}{l}\text { Ogu118- } \\
3 A\end{array}$ & $0.87 *$ & 68.13 & & & \\
\hline Kt-1385B & 1.09 & & $\mathrm{Kt}-18 \mathrm{~B}$ & 2.73 & & & & \\
\hline $\begin{array}{l}\text { Ogu34-1- } \\
8 \AA\end{array}$ & $0.60 *$ & 75.60 & $\begin{array}{l}\text { Ogu308- } \\
6 A\end{array}$ & $5.30 *$ & 17.18 & & & \\
\hline $\begin{array}{l}\text { Kt-34B } \\
\text { (WF) }\end{array}$ & 2.46 & & Kt-308B & 6.40 & & & & \\
\hline
\end{tabular}




\section{Figures}

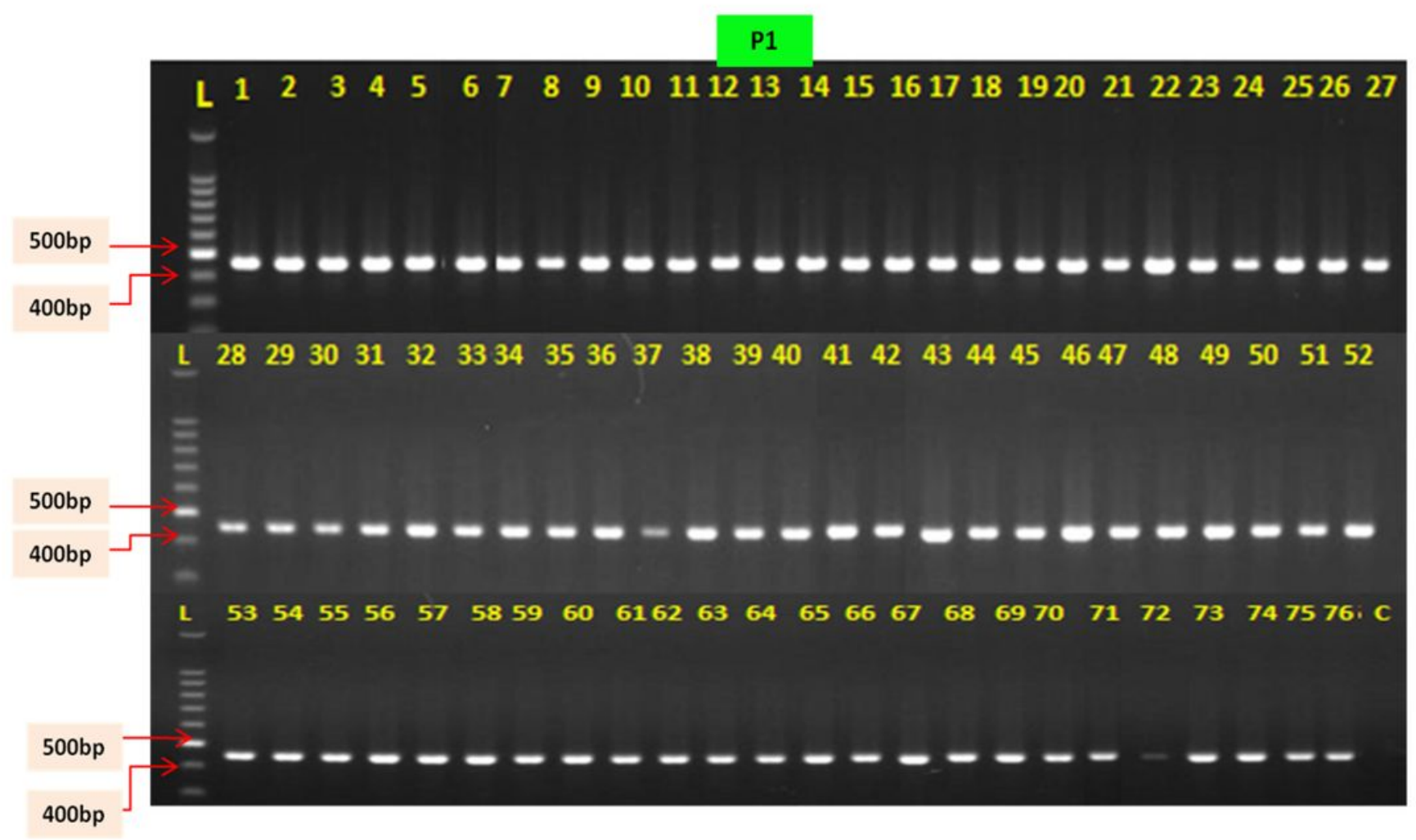

Figure 1

PCR amplification profile of 76 cytolines of cauliflower. The P1 depicts the PCR amplification with primer P1 specific to orf-138, L: ladder, C: control (Sel-27) 
A

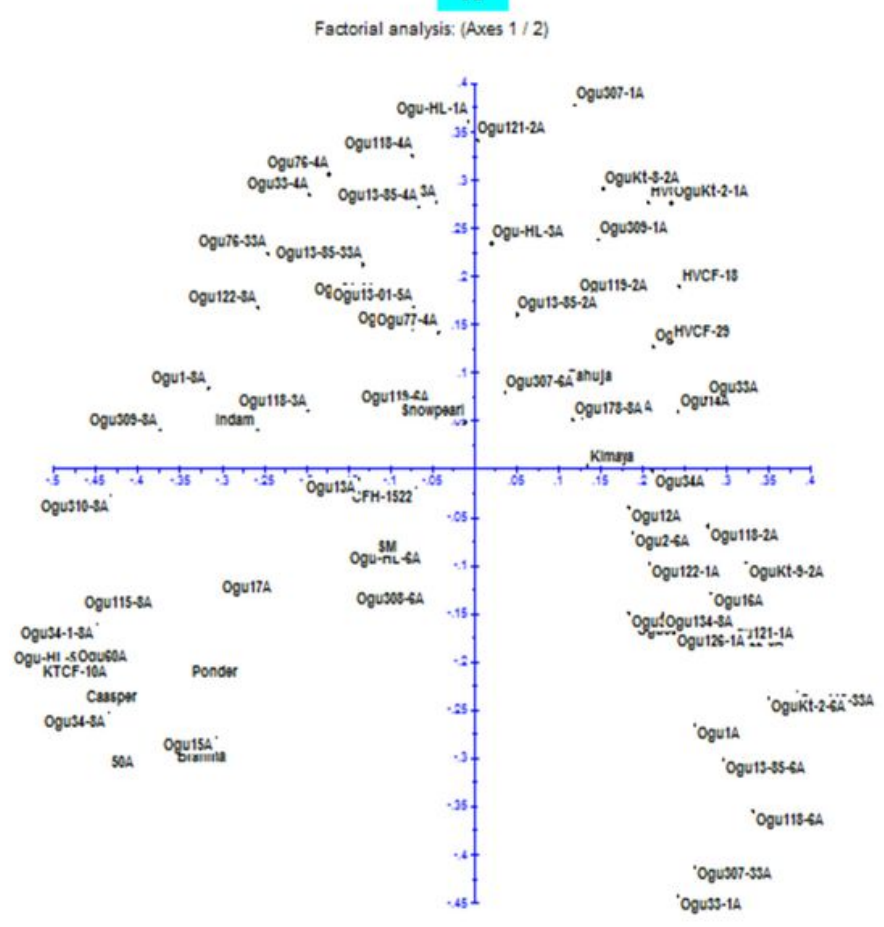

B
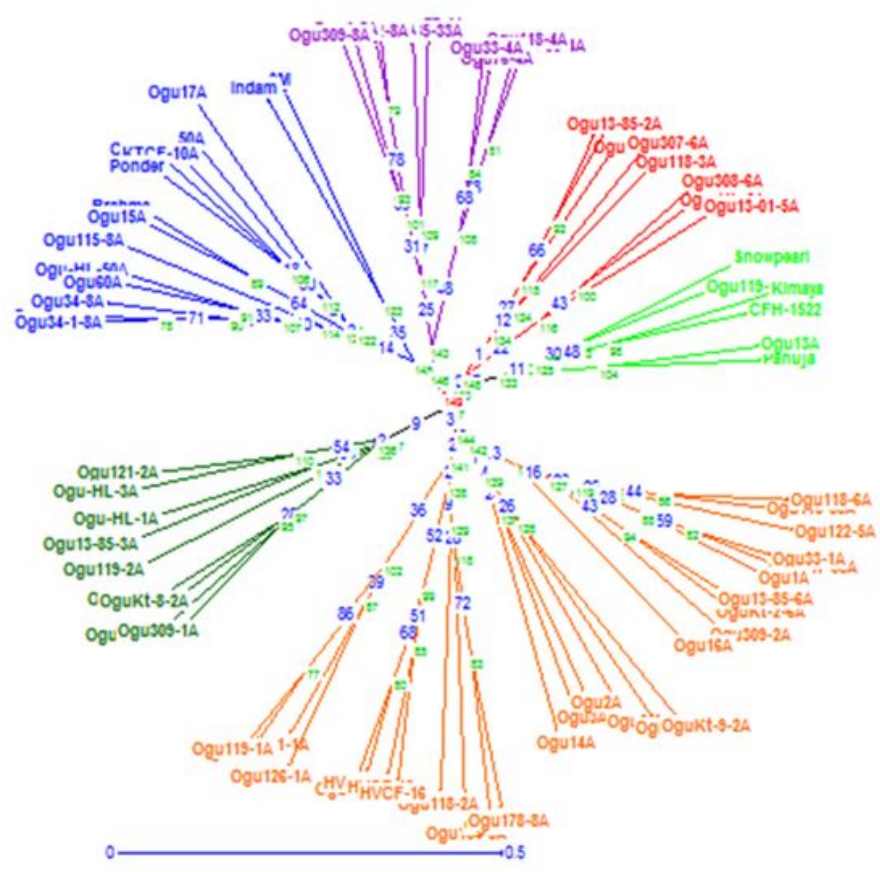

\section{Figure 2}

Principal component analysis and Neighbour joining cluster analysis. The cluster analysisof cauliflower cytolines of varying nuclear genome background based on combined analysis of mt-DNA specific and mt-SSR primers is presented here.(a) Principal component analysis of 76 cytolines based on molecular data (b) NJ dendrogram of cytolines depicting 6 distinct groups in different colors 


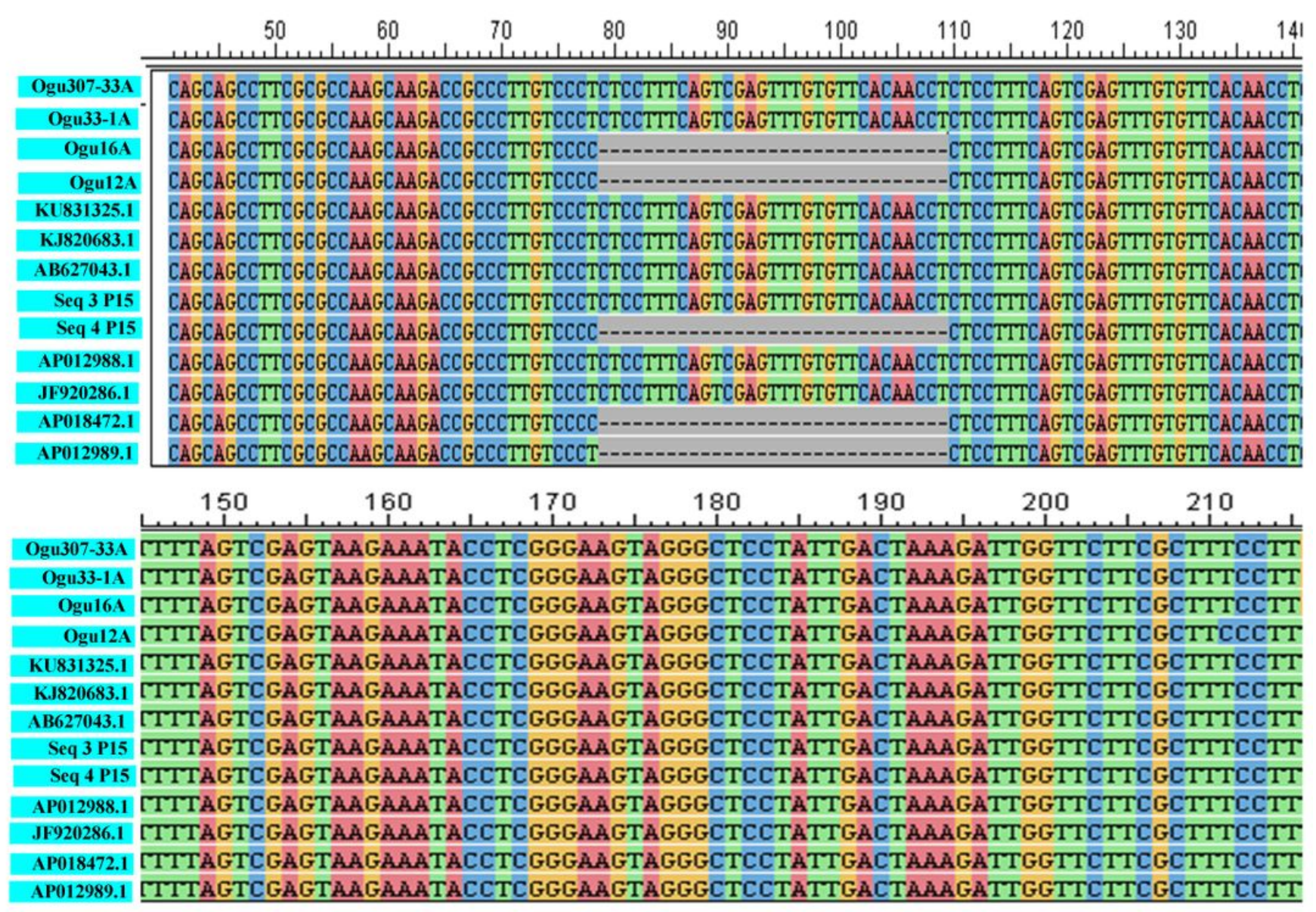

\section{Figure 3}

Sequence analysis and alignment of polymorphic amplicons generated by primer P15.Ogu307-33A (MN549523), Ogu33-1A (MN549524), Ogu16A (MN549525) and Ogu12A (MN549526) are selected polymorphic amplicons of CMS mitotypes. Numbers in parenthesis are accession numbers obtained for the respective fragment sequence submitted to GenBank. KU831325.1 (Brassica oleracea var. capitata), KJ820683.1 (Brassica oleracea var. botrytis), AB627043.1(Brassica oleracea), AP012988.1 (Brassica oleracea), JF920286.1 (Brassica oleracea), AP018472.1 (Raphanus sativus) and AP012989.1 (Brassica nigra) are related reference mitochondrial genome sequences of Brassicaceae crops available in NCBI gene bank database. 
Ogu50A

Ogul2A

Ogu 121-2A

Ogu-HL-3A

Ogu17A

AP018472.1

MG872827.

JF920287.1

Seq5 P16

Seq6 Pl6

AP012990.1

AP012989.1

$\mathrm{AB} 694744.1$

KU83125.1

KJ820683.1

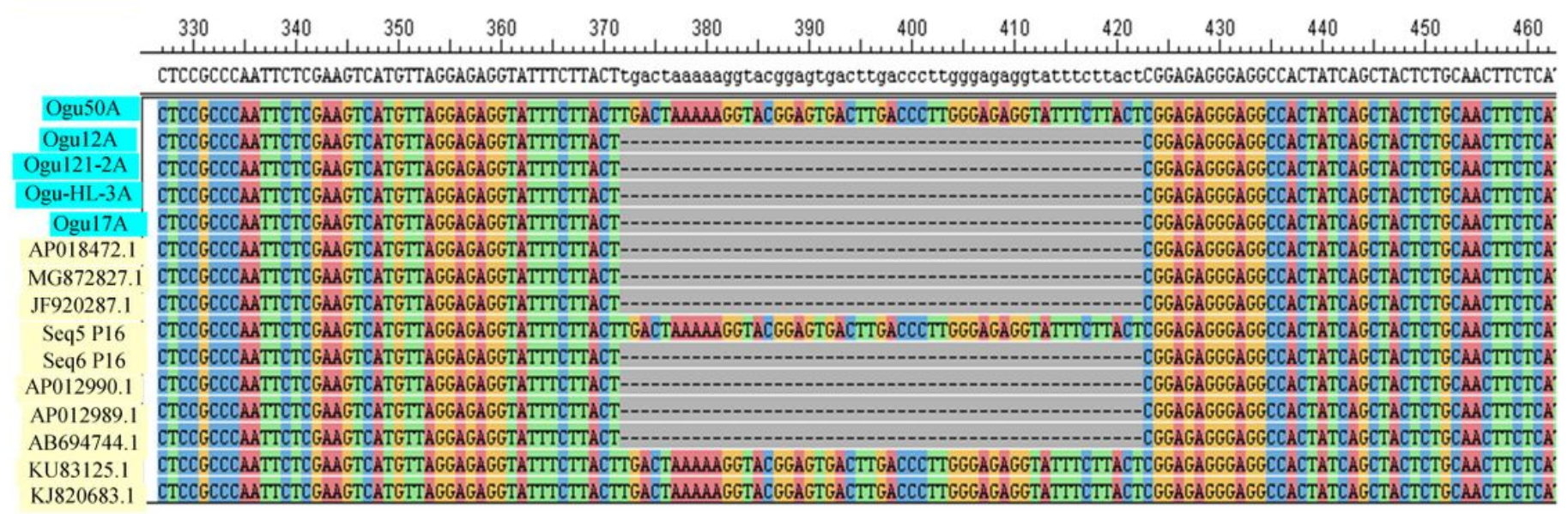

\section{Figure 4}

Sequence analysis and alignment of polymorphic amplicons generated by primer P16. Ogu50A (MN549531), Ogu12A-orf125 (MN549527), Ogu17A (MN549530), OguHL-3A (MN549529) and Ogu121-2A (MN549528) are selected polymorphic amplicons of cauliflower CMS mitotypes. Numbers in parenthesis are accession numbers obtained for the respective fragment sequence submitted to GenBank.KU831325.1 (Brassica oleracea var. capitata), KJ820683.1 (Brassica oleracea var. botrytis), AB694744.1 (Raphanus sativus), AP012990.1 (Raphanus sativus), JF920287.1 (Brassica carinata), AP018472.1 (Raphanus sativus), AP012989.1 (Brassica nigra), and MG872827.1 (Brassica juncea) are related reference mitochondrial genome sequences of Brassicaceae crops available in NCBI gene bank database. 

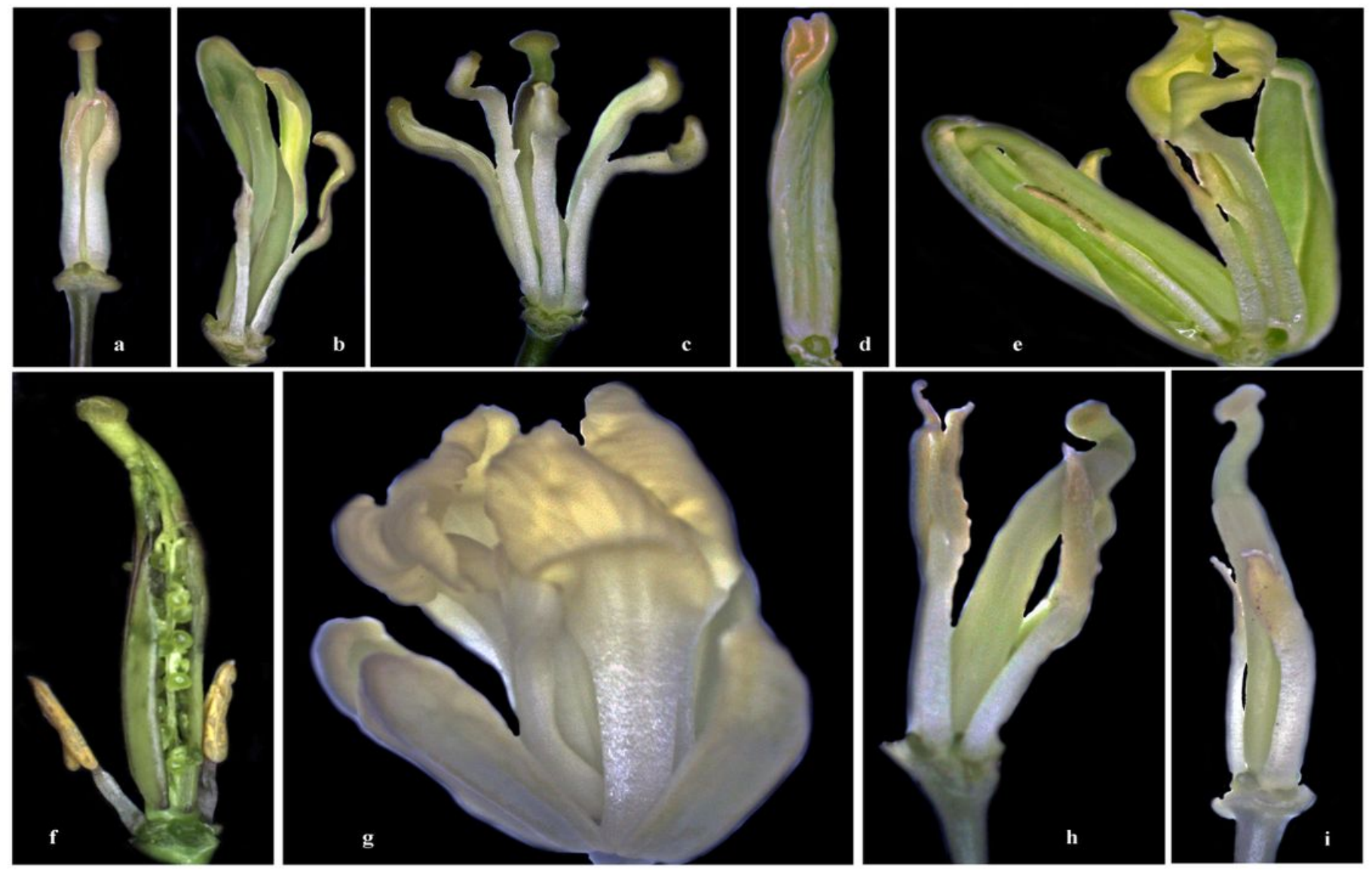

\section{Figure 5}

Floral deformities associated with cyto-nuclear conflict. (a) Adherence of functional stamens with style (b) petaloidy condition of stamens (c) partial petaloidy of functional stamens (d) splitted style along with adherence of stamens (e) stigma hidden inside the petals (f) splitted style (g) unopened flower (h-i) stamens adherence with style and bent stigma 
MN549528

MN549529

MN549531

KU831325.1

IN549530

MN549527

AP012990.1

AB6997444.1

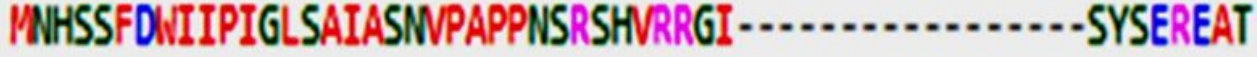
INHSSFDVIIPIGLSAIASNPAPPNSRSHVRRGI.................... SYSEREAT INHSSFDUIIPIGLSAIASMPAPPNSRSHVRRGISYLTKKVRSDLTLGRGISYSEREAT INHSSFDVIIPIGLSAIASNPAPPNSRSHVRRGISYLTKKVRSDLTLGRGISYSEREAT INHSSFDVIIPIGLSAIASNPAPPNSRSHVRRGI....................SYSEREAT WNHSSFDVIIPIGLSAIASMPAPPNSRSHVRRGI.................... SYSEREAT INHSSFOWIIPIGLSAIASMPAPPNSRSHVRRGI...................SYSEREAT WNHSSFDVIIPIGLSAIASNPAPPNSRSHVRRGI SYSEREAT $\$ * * * * * * * * * * * * * * * * * * * * * * 8 * * * * * * * * * * *$

\section{Figure 6}

Amino acid sequence analysis of ORFs of P16 polymorphic amplicons. MN549531, MN549527, MN549530, MN549529 and MN549528 are selected protein sequences of ORFs of cauliflower CMS mitotypes.KU831325.1 (Brassica oleracea var. capitata), AB694744.1 (Raphanus sativus), AP012990.1 (Raphanus sativus) are reference amino acid sequences of Brassicaceaeobtained by NCBI ORF finder. 

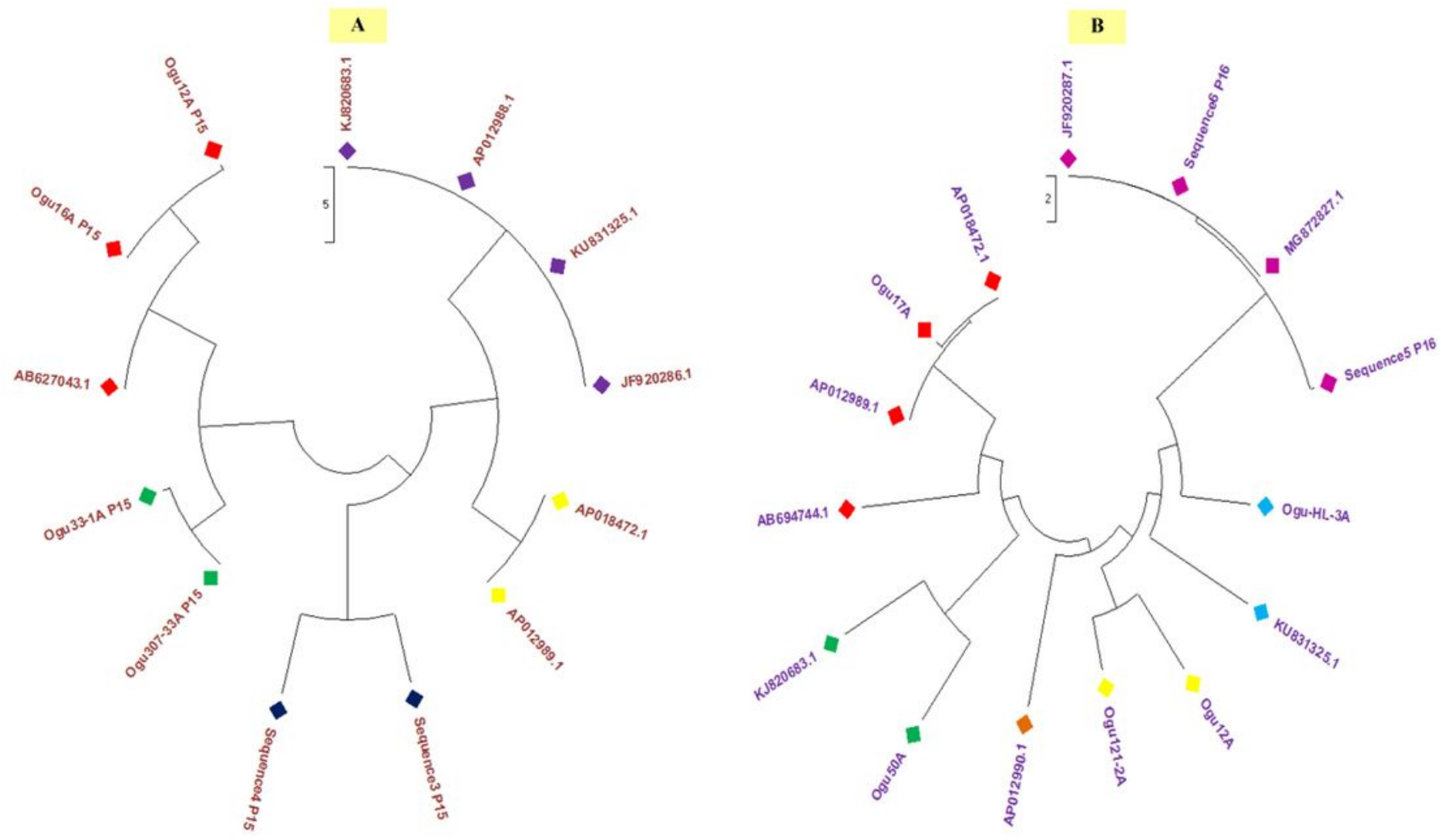

\section{Figure 7}

Phylogenetic analysis(a) Phylogenetic tree based on sequence analysis of selected polymorphic fragments generated with primer P15 and related reference mitogenome sequences from NCBI gene bank database. (b) Phylogenetic tree based on sequence analysis of selected polymorphic amplicons generated with primer P16 and related reference mitogenome sequences from NCBI gene bank database. 


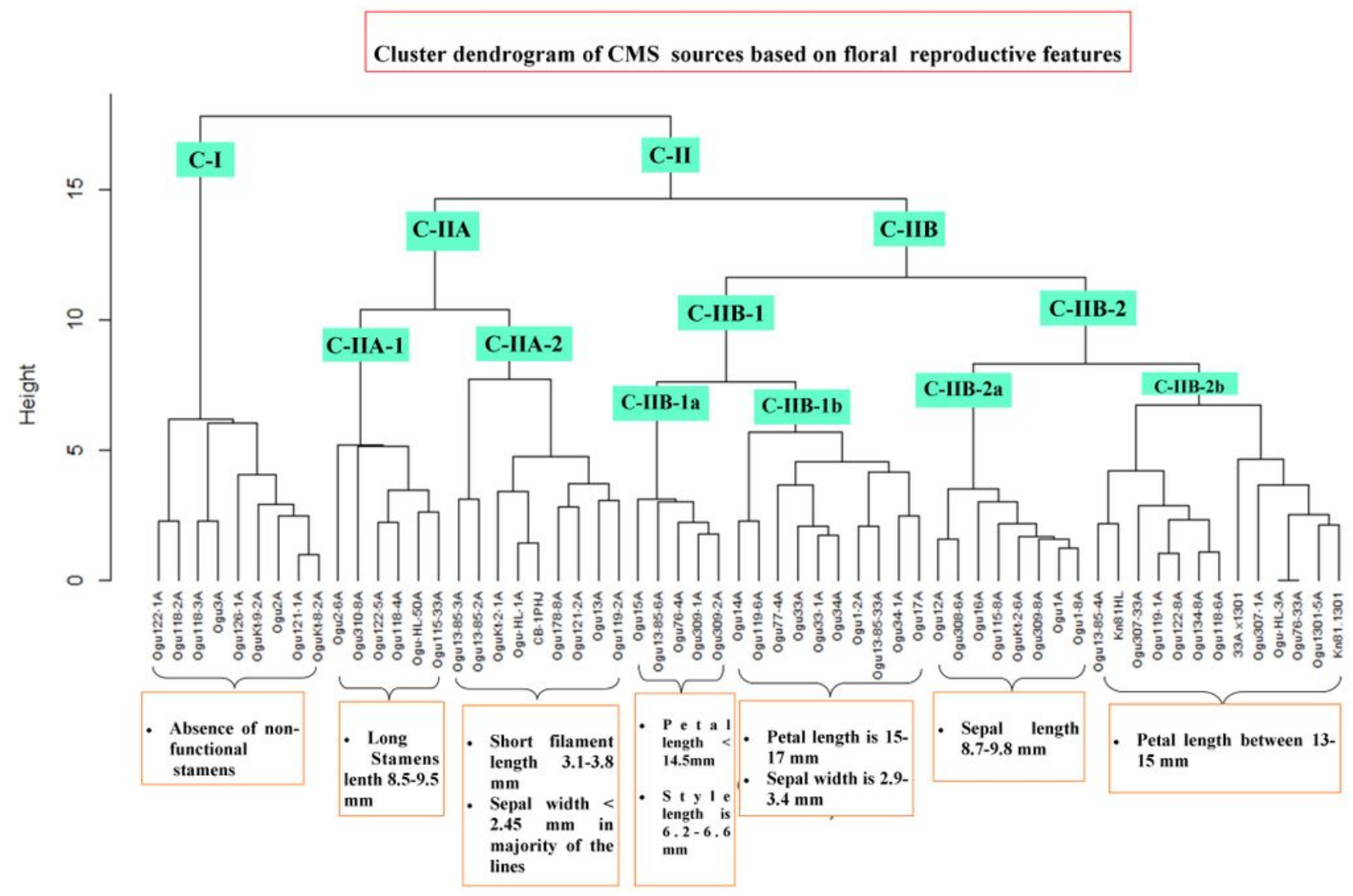

Figure 8

Cluster dendrogram of cauliflower cytoplasmic sources based on floral traits. Cluster C-I harbor all the CMS mitotypes without non functional stamens. Cluster C-II comprises different sub-clusters with varying degree of floral phenotypic variability and abnormalities.

\section{Supplementary Files}

This is a list of supplementary files associated with this preprint. Click to download.

- FigureS2.JPEG

- Figures1.TIF

- Additionalfile1.docx 